\title{
C. Auf der Suche nach Milo von Reims und Trier Oder: Die Konstruktion eines Erzbischofs
}

\section{Wer war Milo? - Fragen an ein verspätetes Bischofsgrab}

Als in den beiden Jahren 1989 und 1990 Sanierungsarbeiten an der Pfarrkirche St. Peter in Trier-Ehrang stattfanden, nutzte man diese Gelegenheit auch für Grabungen, um der Vorgeschichte des heutigen Kirchenbaus auf die Spur zu kommen. Dabei richtete sich das Interesse auch auf das Grab eines ehemaligen Trierer Bischofs - eines gewissen Milo -, der in dieser Kirche nach einem Jagdunfall in der Mitte des 8. Jahrhunderts seine letzte Ruhestätte gefunden haben sollte. So berichtet der wohl im dritten Viertel des 11. Jahrhunderts entstandene Libellus de rebus Treverensibus dazu folgendes: ${ }^{1}$

„[... im 39ten Jahre und 10ten Monat seiner Tyrannei wurde er (Milo) auf der Jagd von einem Eber durchbohrt; er starb in dem Weiler, der Ehrang genannt wird, am ersten Meilenstein vor der Stadt Trier. Dort wurde er in der Kirche des Apostelfürsten Petrus beerdigt, auf der rechten Seite neben dem Altar. “2

Die um 1101 ebenfalls in Trier entstandenen Gesta Treverorum griffen das wieder auf und berichten ganz ähnlich: ${ }^{3}$

„Der Gewaltherrscher Milo aber wurde nach den oben geschilderten Ereignissen, während er mit Eifer auf der Jagd war, von einem Eber durchbohrt und starb in

1 Vgl. dazu letztmals und mit einer überzeugenden Umdatierung des Libellus' in die genannte Zeit sowie der Diskussion der bisherigen Literatur KöLzer, Studien, S. $252-$ 260. Der Verfasser wolle vor allem erklären, wer das Kloster Oeren gegründet habe und wie es in den Besitz der Trierer Erzbischöfe übergegangen sei (ebd., S. 254). In deren Umfeld müsse man ihn auch suchen. - Zuvor und noch anders PoensGen, Geschichtskonstruktionen, S. 94-143, die von einer Entstehung 1011-1015 (ebd., S. 138) ausgeht. Werner, Anfänge, S. 4-11. Anton, Liutwin, S. 34, Anm. 35, mit weiterer Literatur.

2 Vgl. Weber, Ausgrabungen, S. 90. De rebus Treverensibus saec. VIII-X libellus cap. 9, ed. Waitz, S. 103: Non multo autem tempore interposito Milo tyrannus, qui hanc Treverensem ac Remensem invaserat sedem, anno tyrannidis sue 39, et mense decimo ab apro, dum venatur, percussus, moritur in villa, que Ierancus dicitur, primo ab urbe Treverica miliario; ubi et sepelitur in ecclesia sancti Petri principis apostolorum latere secus altarę.

3 Vgl. dazu Poensgen, Geschichtskonstruktionen, S. 120-134. Winheller, Lebensbeschreibungen, S. 104-106, 168, 171. Thomas, Studien, S. 23-152. Der Text sei vielleicht in St. Eucherius verfaßt (ebd., S. 27). KöLzer, Studien, S. 252. Werner, Anfänge, S. 23. 
einem Weiler, der Ehrang heißt, am ersten Meilenstein von Trier. Dort wurde er auch bestattet, vierzig Jahre nach Beginn seiner tyrannischen Herrschaft. “4

Der überaus genaue Hinweis auf die Lage des Grabes schien bisher für die Glaubwürdigkeit dieser Angaben zu sprechen. ${ }^{5}$ Doch hat sich bei den Grabungen nicht eine einzige Spur davon gefunden. Womöglich läßt sich das darauf zurückführen, daß der archäologische Befund der angegebenen Stelle durch einen neugotischen Nachfolgebau Ende des 19. Jahrhunderts völlig zerstört wurde. $^{6}$ Was aber noch viel schwerer wiegt: Der älteste nachweisbare dortige Kirchenbau (eine kleine Saalkirche mit Apsis) ist frühestens auf das 11. Jahrhundert datierbar. Zudem handelt es sich bei der angeblichen urkundlichen Ersterwähnung der Ehranger Peterskirche von 973, einer Schenkung des Trierer Erzbischofs Theoderich I. (965-977) an das Kloster St. Maria in ripa (ad martyres), um eine Fälschung des 12. Jahrhunderts. ${ }^{7}$ Auch die Schenkungsurkunde des Besitzes von Ehrang durch Erzbischof Poppo (1016-1047) an dasselbe Kloster von 1030 ist nicht im Original, sondern lediglich einer wohl manipulierten Fassung des 12. Jahrhunderts erhalten. ${ }^{8}$

Der Gesamtbefund wirft damit mehr Fragen auf, als er zu beantworten vermag. Wieso findet sich kein Milo-Grab, obwohl Trierer Quellen dessen Ort doch so genau lokalisieren? Wieso existieren zudem keine früheren Zeugnisse zur Kirche in Ehrang und auch nicht zum Grab? Warum wiederum deckt sich dies so deutlich mit dem archäologischen Befund? Gab es denn überhaupt einen älteren, nicht mehr nachweisbaren Vorgängerkirchbau, in dem Milo bestattet worden sein könnte? Wußte man vor Ort oder in Trier noch darum? Berief man sich dabei womöglich auf eine mündliche Tradition? Oder muß nicht schlechterdings das nahezu zeitgleiche Auftreten der ersten Grabbeschreibung mit der frühesten nachweisbaren Kirche erhebliches Mißtrauen wecken? Die eben genannten Quellen entstanden zudem alle im Trierer Umfeld. Ist das Ganze womöglich eine Trierer Konstruktion des späten 10., 11. oder gar 12. Jahrhunderts? Aus welchem Grund mochte sie erfolgt sein? Wessen Interesse diente sie? Wieso zog man dazu ausgerechnet einen Milo aus dem 8. Jahrhundert heran? Wer überhaupt war dieser „Gewaltherrscher“ Milo, der vierzig Jahre im

4 Vgl. dazu Weber, Ausgrabungen, S. 91. Gesta Treverorum cap. 25, ed. Waitz, S. 162: Milo igitur tirannus, his ita peractis, venationi inserviens, ab apro percussus moritur in villa quae dicitur Arno primo a Treberi miliario, ubi et sepelitur post 40 annos suae tirannicae invasionis.

5 Vgl. dazu Weber, Ausgrabungen, S. 20.

6 Vgl. Weber, Ausgrabungen, S. 22 u. 105.

7 Vgl. dazu Weber, Ausgrabungen, S. 89 f., 104, mit der Quelle und weiterer Literatur. Vgl. auch MRUB I †244, S. 299-301.

8 Vgl. Weber, Ausgrabungen, S. 89 f. u. 104-106. - Vgl. auch MRUB I †302, S. $353-$ 355. Die heute vorliegende Abschrift befindet sich danach im Officialats-Transsumt von 1497. 
Amt gewesen sein soll? Wann genau lebte er? Was ist über ihn bekannt? Was berichten die zeitgenössischen Quellen? Was spätere Zeugnisse?

Eine der frühesten Spuren in einem Text überhaupt, die die Tyrannei des Milo thematisiert, findet man - wie wir schon gesehen haben - erst in einer Denkschrift des Erzbischofs Hinkmar von Reims (845-882). Dieser verfaßte sie im Jahr 863 - also etwa ein Jahrhundert nach Milo. Erhalten ist sie - wie oben gesehen - singulär, jedoch in einer nahezu zeitgleichen Handschrift: In Remo autem et in Treveri, quas Milo - tonsura, non vita clericus - occupaverat, [....${ }^{9}$ Hinkmar spricht darin von einem Milo, der zwar durch die Tonsur, nicht aber durch sein Leben Kleriker gewesen sei und der Reims wie Trier gemeinsam unrechtmäßig okkupiert habe. Damit meint er wohl eine gemeinsame Besetzung der Bistumssitze beider Städte. Dieses Phänomen eines Doppelbistums erscheint bemerkenswert genug. Doch wann genau soll Milo diese beiden Orte besetzt haben? Wirklich präzise Daten dazu gibt es nämlich nicht. Und die wenigen weiteren schriftlichen Angaben zu ihm, die sich finden, sind zeitlich breit gestreut und zudem äußerst widersprüchlich. Denn man muß die ebenfalls teils unsicher überlieferten - Amtszeiten der späteren sowie früheren Trierer und Reimser Bischöfe heranziehen, um zu einem bisher in der Forschung vertretenen, aber lediglich errechneten Annäherungswert von zwischen $722 / 3-761 / 2$ zu gelangen. ${ }^{10}$ Doch bleibt auch das problematisch. Nicht zu Unrecht hat deshalb schon Hermann Sснмidt 1929 zum von Hinkmar beschriebenen Phänomen bemerkt: „Über den Beginn der ungeordneten Beziehungen zwischen Trier und Reims liegen keine gleichzeitigen Nachrichten vor. ${ }^{\text {‘11 }}$

Zumindest ist dieses hier grob gezeichnete Bild Milos von der bisherigen Forschungsliteratur immer wieder bestätigt bzw. fortgeschrieben worden. Grundlegend dazu ist die Studie Eugen Ewigs von 1954, der gleichsam alle greifbaren frühen und späteren Quellenbelege gleichwertig wie in einem Puzzle zusammengesetzt hat und als Ergebnis einen Trierer Okkupanten des Reimser Bistums, ja einen Entfremder von Kirchengut sowie Gegner seines eigenen Zeitgenossen Bonifatius sieht. Milo sei nicht einmal wirklich Bischof gewesen, andere hätten an seiner Stelle in Reims als solcher fungiert. Doch gibt EwIG auch zu, daß Einzelheiten über Milos Amtsführung in Reims nicht überliefert sind und daß über Milos angebliches Unwesen in Trier dann sogar erst Trierer

9 Vgl. Hinkmar, Denkschrift cap. I,8, ed. Perels, S. 77 (= MGH Epp. 8/1, ed. Perels, S. 126). Vgl. dazu unten S. 88 f. u. Anm. 69 f., sowie oben Kap. A.I.

10 Vgl. dazu hier zusammenfassend Anton, Milo, Sp. 627 f. - Sснмidt, Trier und Reims, S. 42-47, geht dagegen beispielsweise von einer Herrschaft Milos in Reims seit 717 aus, die bis 757 gewährt haben könnte. Doch handelt es sich dabei um reine Rechenspiele. So habe Milo gleichzeitig mit dem Reimser Bischof Tilpin in Reims agiert.

11 Vgl. Sснмidt, Trier und Reims, S. 37, der auch (ebd., S. 37 f.) die schwierige Quellensituation zusammenfaßt. 
Texte des 11. Jahrhunderts berichten. Er spricht bei diesen Quellen häufig von „späteren Fälschungen, die aber sicher einen echten Kern enthalten“. In seinen nachfolgenden Arbeiten zu Trier hat EwIG an seinen Ergebnissen festgehalten. ${ }^{12}$ Im selben Jahr hat Theodor SCHIEFFER seine einschlägige Studie zu Bonifatius veröffentlicht und ist darin dem gängigen Milobild gefolgt. ${ }^{13}$ Guntram ScHenk zu Schweinsberg hat 1971 nochmals die entscheidenden Belege zusammengetragen und in seinem Urteil EwIG weitestgehend bestätigt. Gleiches gilt für die aktuellen Trierer Arbeiten Hans Hubert Antons. Milo wird dann auch als ein einschlägiges Beispiel für einen verweltlichten Bischof der späten Merowinger- und frühen Karolingerzeit genannt. Darin folgen auch alle weiteren Studien, die sich mit Milo beschäftigen, bis zum gerade erschienenen ersten Band der „Geschichte des Bistums Trier" und Lutz E. von Padbergs kleine Monographie zu Bonifatius. ${ }^{14}$

12 Vgl. dazu Ewig, Milo, S. 413-421. Das Zitat S. 414. Ewig folgt sogar Trierer Quellen des 10.-12. Jahrhunderts, die vor Milo bereits dessen Vater und Vorgänger Liutwin über die Bistümer Trier, Reims und Laon verfügen sahen. Vgl. dazu unten Kap. C.IV. u. Kap. D.VI.3.ff. Ewig, Trier, S. 141-143. EwIG, Treverensia, S. 229 f., worin er aufgrund der oben genannten Denkschrift (vgl. Kap. A.I.) Söhne Milos als nachgewiesen betrachtet. Diese seien allerdings illegitim. - Dabei decken sich die hier gemachten chronologischen Aussagen nicht mit denen in seinem ersten Artikel zu Milo. - Schon Sснміdт, Trier und Reims, S. 35 f., 38-58, stellt die Berichte zusammen, die nicht an die Ausübung bischöflicher Funktionen durch Milo in Reims glauben. Vgl. ferner Prinz, Klerus, S. 6669. Prinz, Frühes Mönchtum, S. 197-200. Krusch, Remigius-Fälschungen, S. 513 f. Die älteste Darstellung findet sich bei Brower/Masen, Antiquitates, S. 361-372.

13 Vgl. Schieffer, Winfrid-Bonifatius, S. 101, 130 f., 209 f., 220, 227, 229, 241, 252, 255 f., 265, 277.

14 Vgl. Schenk zu Schweinsberg, Reims, S. 164-171, der aber (ebd., S. 165) eine Doppelherrschaft bereits unter Liutwin ablehnt. Anton, Trier im frühen Mittelalter, S. 103 f., 121, 158, 160-162. Anton, Trier vom Beginn des 6. bis zum Ende des 8 . Jahrhunderts, S. 43, 49-51, 66 f. Anton, Trier in der hohen und späten Karolingerzeit, S. 104, 107. Bienert, Besiedlung Triers, S. 130, 135 f., 138. Anton, Milo. Anton, Liutwin, Anm. 28 u. S. 36-38, 43-45, 48, 50 f. Gierlich, Grabstätten, S. 54-56, zu seinem Grab, der an eine Bestattung in Ehrang glaubt. Anton, Raumbestimmende Voraussetzungen, S. 161-166. Pfeiffer, Die frühe fränkische Zeit, S. 237 ff., bes. S. 242-246. BAuER, Verehrung heiliger Trierer Bischöfe, S. 400, weist darauf hin, daß bei Milo keine Belege für Memoria vorliegen. Auch werde er nicht als Heiliger verehrt. Lediglich die Mettlacher Miracula s. Liutwini bewahrten ihm ein gutes Andenken. VoN Padberg, Bonifatius, S. 66, 71-74. - Vgl. als weitere Auswahl nur RaAch, Mettlach, S. 15-18, 21 f., 27-33, der (ebd., S. 17) sogar davon ausgeht, daß Milo über Bischöfe in Trier verfügt haben muß, weil sein Weihegrad der eines Diakons gewesen sei. Semmler, Episcopi potestas, S. 318 f., 371-373. Semmler, Sukzessionskrise, S. 20, 25 f. Kaiser, Bischofsherrschaft, S. 61 f., 540 f. Wallace-Hadrill, Frankish Church, S. 137 u. 160, der für Milo sogar ein Episkopat in Laon annimmt. Hioki, Stadtherrschaft. Insgesamt berühren all diese Fragen zudem die Überlegungen der Forschung zu den frühen sog. Bischofsstaaten der Merowinger- und frühen Karolingerzeit, die teilweise auf weitaus späteren Quellen basieren. Doch soll dem an dieser Stelle nicht nachgegangen 
Auch hier bietet es sich erneut an, auf die anfangs beschriebene methodische Vorgehensweise zurückzugreifen: Möglichen Konstruktions- bzw. Verformungsprozessen bei Berichten und Nachrichten über ein Ereignis - also Geschichts- und damit auch Erinnerungsbildern - wird nachzugehen sein. Dazu müssen die entsprechenden Quellen in chronologischer Folge vom Ereignis ausgehend, in die spätere Zeit fortschreitend nacheinander geprüft und die jeweiligen Entstehungsbezüge als Konstruktions- bzw. Verformungsfaktoren der Geschichtsbilder berücksichtigt werden.

Eben das soll deshalb im folgenden bei den Berichten und Belegen zum von Hinkmar in seiner Denkschrift erwähnten „Doppelbischof" und Okkupanten Milo versucht werden. Zunächst werden erstens sowohl für Reims wie auch Trier die wenigen zeitgenössischen Belege des 8. Jahrhunderts untersucht, um dann zweitens dem Bild des in den Quellen seit der Mitte des 9. Jahrhunderts plötzlich immer schillernder hervortretenden Milos nachzugehen. Dabei müssen auch Bischöfe an diesen Orten, deren Amtszeiten sich mit den errechneten Milos überschneiden, teilweise berücksichtigt werden. Schließlich wird drittens in einem letzten Schritt - die plötzlich auftretende Trierer Überlieferung im weiteren Umfeld des 10. und 11. Jahrhunderts ins Auge zu fassen sein.

\section{Die zeitgenössischen Quellen aus dem 8. Jahrhundert}

\section{Eine Urkunde aus Metz von 715}

Beginnen wir mit dem 8. Jahrhundert. Die früheste mögliche zeitgenössische Erwähnung eines Milo, den die Forschung mit unserem Milo in Verbindung bringt, findet sich im Zeugeneintrag einer Urkunde vom 24. oder 25. Juni 715 aus Metz. Der sacerdos Hugo, sein Bruder Herzog Arnulf, Pippin und Godefridus machen darin eine Schenkung an das Apostelkloster bei Metz (später: St. Arnulf). Doch ist deren Echtheit umstritten. Milo erscheint in einer Zeugenliste im Kontext mehrerer Namen, die die bisherige genealogische Forschung der Familie der sog. ,Widonen-Lambertiner-Miloniden' zugeordnet hat: Actum Mettis publice sub die et tempore ut supra. S. Hugo acsi peccator sacerdos hanc delegationem sive testamentum a me factum firmavi et subscripsi. S. Arnulfus dux hunc testamentum consentiens subscripsi. S. Milonis. S. Uuidonis comitis. S. Eremberti comitis. signum † Lamtberti comitis. signum † Uuarnarii comitis. Allerdings wird dieser Milo mit keiner genauen Bezeichnung genannt. Negativ zumindest fällt er nicht auf. HeIdrich hält diese Liste jedoch aufgrund ihrer

werden. Vgl. dazu die zahlreichen Arbeiten von Semmler, Episcopi potestas. Prinz, Klerus. Heinzelmann, Bischofsherrschaft. Müller, Lyon. Kaiser, Bischofsherrschaft. 
Überlieferungsform berechtigterweise für eine spätere Interpolation. ${ }^{15}$ Hinkmar dürfte sie wohl kaum gekannt haben.

\section{Die Korrespondenz des Bonifatius mit dem Papst}

Die älteste und ganz sicher für uns noch greifbare Erwähnung eines Milo, der zudem zu den Angaben Hinkmars paßt, findet sich in einem Brief des Papstes Zacharias I. (741-752) von 751 an den Angelsachsen Winfried-Bonifatius $(\dagger 754)$. Überliefert ist er in dessen Briefsammlung, die sein Nachfolger Lul noch vor seinem Tod 786 aus den in Mainz erhaltenen Beständen anlegen ließ. ${ }^{16}$ Der Papst antwortet darin dem Missionsbischof auf eine Anfrage: „Was aber Milo und seinesgleichen anbetrifft, die den Kirchen sehr viel schaden, so predige nach dem Wort des Apostels, ob gelegen oder ungelegen, sie sollen von einem so ruchlosen Treiben ablassen". ${ }^{17}$ Zacharias wird jedoch nicht konkreter, ja nennt

15 Vgl. Wolfram, Kritische Bemerkungen, Nr. 6, S. $42-44$ u. 49, hier S. 44. Urkunden der Arnulfinger, ed. Heidrich, S. 75, Anm. ee. Vgl. die jüngste Edition der Urkunde ebd. 8, S. 71-75, die sie für echt hält. Zur Frage der Echtheit und der interpolierten Zeugenliste vgl. ebd., S. 72 f. (Wolframs A genannte, oben zitierte Textfassung entspricht der Fassung $B_{1}$ Heidrichs). Die Zeugenliste ist in zwei Einzelabschriften in Urkundenform aus dem 12. Jahrhundert interpoliert (eine ist oben wiedergegeben), jedoch nicht in zwei Chartularabschriften des 13. Jahrhunderts, die dem Original näher stünden. Denn die Urkundenabschriften enthielten gegenüber der Chartularfassung weitere Interpolationen. - In einer angeblichen Urkunde, in der der Trierer Bischof Liutwin am 1. Februar 706 eine Schenkung an das Trierer Stift St. Eucharius vornimmt, erscheint ein Milo diaconus als Zeuge. Vgl. MRUB I 7a, S. 9 f., hier S. 10. Die dürfte aber frühestens im 10. Jahrhundert, viel wahrscheinlicher jedoch später in Trier oder Echternach konstruiert worden sein. Vgl. dazu nur Ewig, Milo, S. 419. Anton, Liutwin, S. 31 u. Anm. 28. Vgl. ausführlich zu dieser Urkunde und den Entstehungsumständen unten Kap. D.III.1. - Wolfram, Kritische Bemerkungen, Nr. 5, S. 42, führt noch eine weitere Urkunde auf, in der Milo möglicherweise als Zeuge fungiert. Es handelt sich dabei um eine Schenkung des Drogosohns Arnulf an das Apostelkloster bei Metz vom 27. Juni 706, die aber sicher eine Fälschung ist (ebd., S. 50). So fällt auch die Einschätzung bei Urkunden der Arnulfinger 30, ed. Heidrich, S. 130-135, aus, die jedoch auf 704 oder 706 datiert. Die Zeugenliste ähnelt derjenigen der oben genannten Urkunde und enthält noch weitere Namen. - Zu den sog. ,Widonen-Lambertinern-Miloniden' vgl. zusammenfassend mit weiterer Literatur Hlawitschka, Widonen (Lambertiner). RaAch, Mettlach, S. 23-36, sowie ausführlich unten Kap. D.IV.6.d.

16 Vgl. zuletzt Briefe des Bonifatius, ed. Rau, S. 9-22. Die Handschriftenklasse 1 entstand gegen Ende des 8. Jahrhunderts. Die Klasse 2 ist eine erste Redaktionsstufe aus Mainz. Sie könnte noch kurz vor Luls Tod 786 fertiggestellt worden sein. Vgl. dazu WATTENвach-Levison-Löwe, Geschichtsquellen 2, S. 175 f. Tangl, Studien.

17 Vgl. Briefe des Bonifatius, ed. Rau, S. 299. Vgl. dazu Epp. Bonifatii 87, ed. Tangl, S. 194-201, hier S. 198: De Milone autem et eiusmodi similibus, qui ęclesiis Dei plurimum nocent, ut a tali nefario opere recedant, iuxta apostoli vocem oportune inportunae predica. 
nicht einmal die genaue Funktion dieses Milo. Ganz offenbar aber muß sich Bonifatius in einem überaus starken Konflikt mit ihm befunden haben. Darüber ist viel spekuliert worden: Vielleicht stand Milo in irgendeiner Form auf der Seite des traditionellen fränkischen Klerus', der sich gegen die Kirchenreform des Bonifatius sträubte. Bonifatius strebte im Frühjahr 744 die Errichtung von drei Erzbischofssitzen mit konkreten Kandidaten im Frankenreich an - nachdem es dieses Amt dort schon lange nicht mehr gegeben hatte -, wie sich aus seiner Briefkorrespondenz und aus dem Konzilsprotokoll von Soissons 744 rekonstruieren läßt: 1. ein Grimo war für Rouen vorgesehen, 2. ein Hartbert für Sens und 3. ein Abel für Reims. Doch setzte sich offenbar nur Grimo durch, wie aus einem Brief des Zacharias vom 5. November 744 hervorgeht, der bei Bonifatius erstaunt anfragt, warum dieser nun nur noch das Pallium für jenen einen benötige. ${ }^{18}$ Das heißt allerdings nicht, daß Abel nicht wenigstens einfacher

18 Papst Zacharias bestätigt allen dreien am 22. Juni 744 das Pallium. Vgl. dazu Epp. Bonifatii 57, ed. TANGL, S. $102-105$, bes. S. 103: De episcopis vero metropolitanis, id est Grimo, quem nos iam conpertum habemus, Abel sive Hartbercto, quos per unamquamque metropolim per provincias constituisti, hos per tuum testimonium confirmamus et pallia dirigimus ad eorum firmissimam stabilitatem et ecclesiae Dei augmentum, ut in meliori proficiant statu. - Dann fragt er aber bei Bonifatius nach, warum dieser nun lediglich noch das Pallium für Grimo fordere. Vgl. ebd. 58, S. 105-108, bes. S. 106 (5. November 744): [...], quia tres archiepiscopos per singulas metropolim ordinasses, reseruisti, id est Grimonem in civitate, quae dicitur Rodoma, secundum vero Abel in civitate, quae dicitur Remorum, tertium denique Hartbertum in civitate, quae dicitur Sennis. Qui et apud nos fuit et tua nobis pariter et Carlomanni atque Pipini detulit scripta, per quae suggessistis, ut tria pallea hisdem tribus prenominatis metropolitanis dirigere deberemus; quod et largiti sumus pro adunatione et reformatione ęclesiarum Christi. Nunc autem denuo tuas suscipientes syllabas valde sumus, ut diximus, mirati, eo quod antea nobis una cum memoratis principibus Galliarum pro tribus palliis suggessisti et postea pro solo Grimone. Sed volumus, ut nobis tua indicet fraternitas, cur nobis ita direxisti antea pro tribus et postmodum pro uno, ut et nos certi redditi ex hoc nulla in nobis sit ambiguitas. Offenbar warf Bonifatius in diesem Zusammenhang dem Papst sogar Simonie, ja Käuflichkeit der Pallien vor, worauf dieser ausgesprochen erbost in dieser Antwort an Bonifatius reagierte. - Die Erhebung Abels in Reims und Hartberts in Sens beschloß die westfränkische Synode von Soissons am 2./ 3. März 744. Vgl. dazu MGH Conc. 2, S. 34, Z. 12 ff. - Zur Bonifatianischen Reform vgl. hier JARNUT, Reformkonzilien, bes. auch S. 5, 8 f., 15, wo u. a. darauf hingewiesen wird, daß zugleich eine Absetzung Milos nicht erwähnt wird. Semmler, Mönche und Kanoniker. - Zu Abel vgl. zuletzt die Anmerkungen bei Flodoard II,16, ed. STratmann, S. 166 f. - Erst in einem Schreiben vom Sommer 751 an den Papst begründet Bonifatius die damaligen Schwierigkeiten bei der Pallienvergabe. Vgl. dazu Epp. Bonifatii 86, ed. TANGL, S. 193: De eo autem, quod iam preterito tempore de archiepiscopis et de palleis a Romana aecclesia petendis iuxta promissa Francorum sanctitati vestrae notum feci, indulgentiam apostolice sedis flagito, quia quod promiserunt tardantes non impleverunt; et adhuc differtur et ventilatur; quid inde perficere voluerint, ignoratur. Sed mea voluntate impleta esset promissio. Die Franken hätten ihre Zusagen nicht eingehalten. Noch immer würde es hinausgeschoben und besprochen. Man wissen nicht, was einmal davon umgesetzt werde. 
Bischof in Reims geblieben sein könnte und das womöglich auch vor Bonifatius' Plänen schon war. Letztlich setzt die Palliumsverleihung ja voraus, daß der entsprechende Kandidat zuvor zum Bischof geweiht worden war. In einem Brief Bonifatius' an König Æthelbald von Mercien (716-757) aus dem Jahr 746 oder 747 wird Abel wie selbstverständlich als coepiscopus, also Amtsbruder, genannt, von einem Milo ist keine Rede. ${ }^{19}$ Abel muß zu dieser Zeit folglich noch amtierender Bischof in Reims gewesen sein. Es ist somit äußerst unwahrscheinlich, daß Milo gleichzeitig in Reims wirkte, wohl kaum als Bischof. Erst 751 ist ein Milo zudem ja überhaupt genauer bezeugt. Dies widerspricht also deutlich den von der Forschung vertretenen Episkopatsdaten Milos.

Bisher wollte man diesen Gegensatz mit dem Erklärungsmuster möglicher Chorbischöfe auflösen, also Stellvertretern. Damit lehnte man sich an Flodoard von Reims an, der in seiner „Reimser Kirchengeschichte" Mitte des 10. Jahrhunderts andeutet, es gäbe einige, die Abel für einen Chorbischof hielten. Doch ist diese spätere Interpretation letztlich überzeugend? Zwar gibt es Hinweise auf das Chorbischofsamt im Umfeld des Bonifatius. Sollte man zunächst jedoch nicht einen einfacheren Lösungsweg beschreiten ${ }^{20}$

19 Vgl. Epp. Bonifatii 73, ed. TANGL, S. 146-155, hier S. 146, Z. 27. Zu diesem Brief vgl. Nonn, Bild Karl Martells, S. 83-89. Der Brief ist schon deshalb sehr ernst zu nehmen, weil er zusätzlich noch in der englischen Empfängerüberlieferung erhalten ist. - Milo wird in den Bonifatiusbriefen sonst verschwiegen.

20 Vgl. Flodoard II,16, ed. Stratmann, S. 166, Z. 9 f. Zu Flodoard vgl. unten S. 80, 99 f. u. Anm. 45, 98-104. - Vgl. zum Phänomen der Chorbischöfe KоттJE, Chorbischof, der von einem Aufkommen des westkirchlichen Chorbischofsamtes im Umfeld von Bonifatius und Willibrord spricht. Als früheste Stellungnahme eines Papstes zu diesem Amt führt er einen Brief Zacharias' I. von 747 an den Hausmeier Pippin an. Vgl. dazu Codex Carolinus 3, S. 479-487, hier S. 481, wo eine Passage des Konzils von Antiochia mit den Aufgaben des Chorbischofs zitiert wird. Vgl. ferner Epp. Bonifatii 82, ed. TANGL, S. 182, von 748. In der Grußzeile unterscheidet Papst Zacharias nach den angesprochenen Bischöfen weitere Chorbischöfe. Ebd. 93, S. 213, von 752, in dem Bonifatius von Lul als Mainzer Chorbischof spricht. Ebd. 109, S. 235, von 753, in dem Bonifatius von einem Bischof spricht, der einen Chorbischof eingesetzt habe. Die nächsten Zeugnisse liegen erst in der Mitte des 9. Jahrhunderts. - Vgl. hier nur Angenendt, Klosterbischof, mit weiterer Literatur. Jenal, Klosterbischöfe. Felten, Äbte und Laienäbte, S. 38 f. u. Anm. 29, mit einigen ausführlicheren Beispielen. - Doch wird der entsprechende Bischof dabei jeweils explizit als Chorbischof bezeichnet, was für die frühen Quellen zu Abel nicht zutrifft. Vgl. ferner Frank, Klosterbischöfe. - Ewig, Milo, S. 419, und Ewig, Trier, S. 142, zieht dieses Erklärungsmodell heran. Schenk zu Schweinsberg, Reims, S. 168-172, übernimmt ebenfalls dieses Modell und hält die Einsetzung Abels für den Versuch, Milo aus dem Amt zu jagen. Abel sei aber nie Bischof geworden. Vgl. ferner beispielsweise Schmidt, Trier und Reims, S. $41 \mathrm{f}$. Anton, Liutwin, S. 46. - Vgl. dazu noch ausführlicher mit umfangreicher weiterer Literatur unten Kap. D.IV.6.c., Anm. 426. 
3. Eine Urkunde Karls des Großen von 782 (DKarol. I 148)

Die zeitlich nächste Quelle stammt aus Trierer Überlieferung. Es handelt sich um eine undatierte, in Diedenhofen ausgestellte Urkunde Karls des Großen für die Trierer Kirche unter „Erzbischof" Weomad (762-791), die darin das Kloster Mettlach im Saargebiet anstelle der sog. Söhne Lamberts zugesprochen erhält. Mühlbacher möchte sie zu 782 setzen. Doch bleiben das und ihre Glaubwürdigkeit schon deshalb problematisch, weil sie sich lediglich als Abschrift in einem Trierer Chartular aus der Mitte des 14. Jahrhunderts findet ${ }^{21}$ und Weomad für diese Zeit noch unzutreffend als Metropolit erscheint. ${ }^{22}$ Die Urkunde enthält erste genauere Angaben zu einem Milo, der aber nur in Trier auftritt:

Der Hausmeier Karl [Martell, $† 741$ ] habe einem Milo das Kloster Mettlach zu Lehen gegeben. ${ }^{23}$ Später habe dies auch König Pippin getan ${ }^{24}$ und nach Milos Tod dem Bischof Harthamus übertragen. Ein gewisser Bischof Liutwin, Vater von Milo und Wido, habe es (wohl Mettlach) dem Besitz (partibus) der Kirche des hl. Peter in Trier durch seine Urkunden vermacht. Und Milo, der Nachfolger des Bischofs Liutwin, habe Äbte aus Trier in das Kloster geschickt: zunächst Ebro, danach den Bischof Ratbert, danach Bischof Harthamus, der auch nach Milos Tod durch König Pippin belehnt worden sei. Die iustitia von St. Peter aber habe zum episcopium der Stadt Trier gehört. ${ }^{25}$

21 Vgl. DKarol. I 148, S. 200-202. Die Datierung erfolgt über die als Beisitzer genannten Bischöfe. „Petrus wird 781 von Papst Hadrian I. [772-795] zum Bischof von Verdun geweiht." Angilram [von Metz] starb 791. Ein Aufenthalt Karls in dieser Zeit in Diedenhofen ließe sich nur Ende 782/Anfang 783 nachweisen. Glaube man aber dem Frankfurter Kapitular von 794, so habe ein Bischof Petrus, der zwölf Jahre bei Karl in Ungnade gefallen war, auf der dortigen Synode einen Reinigungseid geleistet. Ein Handeln im Dienste Karls vor diesem Datum wäre unwahrscheinlich. - Vgl. auch BM ${ }^{2}$ 261, S. $106 \mathrm{f}$.

22 Vgl. so schon Sснміdт, Trier und Reims, S. 61 f. Die übrigen zeitgenössischen Quellen nennen ihn nur als Bischof. Erst 791 sei er Erzbischof geworden. Dagegen hält es OexLE, Arnulf, S. 328-345, bes. S. 330, 341 f., für möglich, daß Trier schon unter Weomad Metropole wurde. Er geht der Frage nach der Einführung der Metropolitanordnung in Trier umfassend nach. Vgl. dazu auch die Zusammenstellung bei Brower/Masen, Antiquitates, S. 376-384,

23 Vgl. Urkunden der Arnulfinger 67, ed. Нeidrich, S. 159 f.

24 Vgl. ebd. u. ebd. 89, S. 168.

25 Vgl. DKarol. I 148, S. 201, Z. 5-17: [...], id est monasterium quod dicitur Medolago, quod avus noster Karolus quondam maiorum domus Miloni beneficavit et postea domnus et genitor noster Pippinus quondam rex ipsius Miloni beneficavit et post discessum Miloni Harthamo episcopo, et adseruerunt, ut Leodonius quondam episcopus genitor Miloni et Widoni partibus ecclesie sancti Petri, que est constructa infra muros Treverice urbis, per sua strumenta delegasset; et dixerunt, qualiter Milo, qui fuit successor ipsius Leodoni episcopi et eo tempore episcopio sancti Petri Treverice urbis regebat, abbates in ipso monasterio de ipsa 
Die Urkunde besagt nichts Genaues über die Amtszeiten aller in ihr genannten Bischöfe. Milos Wirken läßt sich also nicht exakt datieren, doch muß es zu Beginn des 8. Jahrhunderts gewesen sein. Milo wird dabei weder positiv noch negativ bewertet. Die Frage bleibt, ob diese Urkunde echt ist. Der seltsam widersprüchlich wirkende Inhalt könnte vielleicht einen tatsächlichen mündlichen Rechtsfindungsprozeß widerspiegeln, wie ihn die Urkunde insgesamt beschreibt. ${ }^{26}$ Andererseits mag er auch auf nachträgliche Veränderungen hindeuten. Weomad zumindest dürfte Milo nach dem Inhalt kaum unmittelbar im Bischofsamt gefolgt sein. Ist die Urkunde aber glaubwürdig, wäre mit ihr und dem bereits erwähnten Zachariasbrief dann ein Milo, der Trierer Bischof gewesen sein könnte, vom frühen 8. Jahrhundert bis mindestens zum Jahr 751 gesichert - aber nicht mehr. ${ }^{27}$ Dagegen stehen für Reims vier Belege zu Abel in dieser Zeit. ${ }^{28}$ - Es ist zudem zweifelhaft, ob Hinkmar dieses Diplom kannte. Von seinem Doppelbischof Milo findet sich jedenfalls weder in Reims noch im Trier des 8. Jahrhunderts eine Spur. Im Kapitel zu Liutwin und Basin wird noch ausführlicher auf die Urkunde in Verbindung mit weiteren Diplomen zu Mettlach einzugehen sein. ${ }^{29}$

civitate misisset, id est Ebreo et post Ebreo Ratbertum episcopum et post Ratbertum Harthamum, qui et post discessum Miloni exinde vestitus fuit per beneficium Pippini regis, et tales testes vel scabini ibidem in presentia adfuerunt, qui per sacramenta hoc adfirmaverunt, ut vidissent et certissime cognovissent iusticiam esse sancti Petri ad episcopium Treverice urbis. - Vgl. zur Urkunde hier nur Anton, Liutwin, S. 32 f., 36-39, 43-45. RaAch, Mettlach, S. $12 \mathrm{ff}$.

26 Die Urkunde spricht dann von einer Besetzung dieses Klosters durch einen Lambert, der Bischof Harthamus völlig seines Besitzes beraubt hätte. Lamberts Söhne Wido, Rodold und Warnar wollten nun vor dem Königsgericht ihren Anspruch durchsetzen, scheiterten damit aber, weil sie ganz im Gegensatz zu den Trierern keine Zeugen vorweisen konnten. Deshalb erhielt Trier unter Erzbischof Weomad das Kloster auf immer zurück. So beruhen die meisten Rechtsangaben auf den mündlichen Berichten von Zeugen, vielleicht auch Augenzeugen. Vgl. nochmals DKarol. I 148, S. 201. - Womöglich erklärt sich daraus auch die etwas verschlungene und widersprüchliche Darstellung des Rechtsinhalts. Dieser erinnert verdächtig an den Zustand unter Bischof Egbert von Trier. Vgl. dazu unten S. 101 sowie unten Kap. D.VI.3.a. - Die Forschung hält die in der Urkunde genannten Bischöfe teils für Klosterbischöfe. Vgl. dazu oben S. 73 u. Anm. 20 sowie nochmals unten Kap. D.IV.6.c., Anm. 426.

27 Liutwin wird in der Urkunde auch nicht als Gründer, sondern nur als Schenker Mettlachs genannt, dies ganz im Gegensatz zu den weiter unten diskutierten Quellen zu Liutwin. Vgl. unten Kap. C.IV. sowie Kap. D.IX.

28 Vgl. oben S. 72 f., Anm. 18 f. sowie unten Kap. C.III.11.

29 Vgl. dazu unten insgesamt Kap. D.IV., bes. Kap. D.IV.6. 


\section{Die Überlieferung zu Milo im Reimser Umfeld seit dem 9. Jahrhundert}

\section{Die Gesta abbatum Fontanellensium}

Damit erfolgt bereits der Übergang von den zeitgenössischen Texten zur zweiten Ebene: der Überlieferung des 9. Jahrhunderts. Bevor hier den weiteren Zeugnissen aus Trier und Reims nachgegangen werden soll, ist ein kleiner Exkurs zu einer nicht in diesen Kontext gehörenden Quelle notwendig. An der kontinentalen Küste des Ärmelkanals im Kloster St-Wandrille entstanden die Gesta abbatum Fontanellensium. Ihr erster, hier wesentlicher Teil könnte nach 833 verfaßt worden sein. ${ }^{30}$ Andere Datierungsansätze gehen von um 800 oder der Zeit zwischen 823 und 833 aus. ${ }^{31}$ Dabei muß man auch mehrere Redaktionsstufen annehmen. Der oder die Verfasser verwandten altes Urkundematerial sowie Überlieferungen ihres Klosters und fügten alles zu einzelnen Abtviten zusammen, wobei einige der frühesten Äbte unberücksichtigt blieben. Die Arbeit ist nicht immer stimmig und weist auch einige chronologische Fehler auf. Eine zeitgenössische oder wenigstens zeitnahe Handschrift des Textes hat sich nicht erhalten, so daß sich nicht ausschließen läßt, daß in diesen später noch weiter eingegriffen wurde. ${ }^{32}$

Eine dieser Viten beschäftigt sich erstaunlicherweise mit den Gesta Landonis archiepiscopi Remensis et rectoris coenobii Fontanellensis. ${ }^{33}$ Die Datierungsangaben dieser Vita sind aber umstritten und ergäben etwa $731-733$ oder $732-735$ für

30 Dieser ältere Forschungsansatz findet sich bei Gesta sanctorum Patrum Fontanellensis coenobii, ed. Lohier/Laporte, S. IX-XLI. Vgl. auch Levison, Gesta abbatum Fontanellensium.

31 Vgl. dazu Wood, St Wandrille, S. 4-6, der von der Entstehung des ersten Hauptteils um 800 ausgeht und mehrere Redaktionsstufen vermutet. Die neueste Ausgabe der Gesta bei: Chronique, ed. Pradié, S. XXV-LIV, datiert den ersten Hauptteil des Textes (Abt Wandregisil bis Gervold) auf das Abbatiat des Ansegis (823-833), den zweiten Hauptteil dann auf Fulko (bis Abt Ansegisil, 834-845). Möglicherweise gab es zwei Überarbeitungen. Pradié folgt der Edition von Lohier/Laporte (S. CII). Vgl. insgesamt auch Freise, Fontanelle, sowie Elm, Macht der Weisheit, S. 219 ff.

32 Man ging deshalb davon aus, daß die Viten der frühesten Äbte vermutlich schon als Einzelüberlieferung vorlagen. Vgl. dazu u. a. Chronique, ed. Pradié, S. XXXIf. u. LII. Vgl. z. B. die Vita Lantberti, ed. Levison. - Zu den Handschriften vgl. zuletzt Chronique, ed. Pradié, S. LXXI-LXXXVIII. Bei der ältesten noch erhaltenen, die den Text überliefert, handelt es sich um Havre, Bibliothèque municipale, 332, S. 152-218. Nach längerer Debatte wird sie inzwischen ins 11. Jahrhundert datiert. Diese Handschrift ist wiedergegeben bei Gesta abbatum Fontanellensium, ed. Löwenfeld.

33 Vgl. Gesta sanctorum Patrum Fontanellensis coenobii cap. V, ed. Lohier/Laporte, S. 43-45, hier S. 43. Chronique, ed. Pradié, S. 68-73 u. 212. Vgl. dagegen Gesta abbatum Fontanellensium cap. 9, ed. Löwenfeld, S. 28 f., wo nicht in nummerierte Unterkapitel, sondern lediglich Absätze unterteilt wird. 
Landos Aktivität. ${ }^{34}$ Der Titel des Erzbischofs erweist sich als Anachronismus, weil es zu dieser Zeit im Frankenreich keine Metropolitanverfassung gab. Es dürfte sich eher um einen späteren Nachtrag aufgrund der inzwischen eingeführten Metropolitanordnung im 9. Jahrhundert handeln. ${ }^{35}$ Die Vita selbst umfaßt (nach der Edition von Lohier und Laporte) drei Kapitel bzw. Abschnitte, die sich um ein Immunitätsprivileg Karl Martells für diesen Lando, also eine Urkunde, gruppieren. Lando habe das Amt des Abtes drei Jahre innegehabt und es 731 übernommen. ${ }^{36}$ Immerhin wäre Lando dann ein weiterer Reimser Bischof während der angeblichen, von der Forschung postulierten dortigen Herrschaft Milos. Wie ist das zu erklären? Die Unstimmigkeit läßt den Editor LoHIER schließlich auch vermuten, Lando sei dort während der Ursurpation des Milo Bischof gewesen. ${ }^{37}$ Doch kommt damit nur erneut der Versuch zur Anwendung, anhand von Chor- oder Parallelbischöfen die Widersprüche bei den Reimser Bischöfen aufzulösen. ${ }^{38}$ Oder unterläuft den Gesta hier eine

34 Vgl. ebd., S. 43 f., wo das 12. Jahr König Theuderichs (IV., eigentl. 732-733), das 17. Karl Martells (eigentl. 730-731) und insgesamt das Jahr 731 genannt werden.

35 Aber auch andere Bischöfe treten als Äbte in St-Wandrille auf: so Bainus, Bischof von Thérouanne (701-710) (Gesta sanctorum Patrum Fontanellensis coenobii cap. II, ed. Lohier/Laporte, S. 14-21), Bischof Hugo von Rouen, Paris und Bayeux († ca. 730?), der fälschlicherweise mit dem Titel des Erzbischofs versehen worden ist (ebd. cap. IV, S. 37-43) (BHL 4032) und Erzbischof (?) Raganfred von Rouen (739-741 o. 744747) (ebd. cap. VIII, S. 58-63). Vgl. insgesamt Chronique, ed. Pradié, S. 26-37, 58 67, 94-101, 203-205, $210 \mathrm{f} ., 214 \mathrm{f}$.

36 Vgl. BM ${ }^{2}$ 39, S. 16. Urkunden der Arnulfinger 70, ed. Heidrich, S. 161. Heidrich, Titulatur, S. 161 u. S. 126 ff. - Vgl. dazu ferner NonN, Bild Karl Martells, S. 103 f., der auch nachweist, daß die Gesta die Ann. Mett. prior. als Grundlage für historische Angaben verwenden. - Wood, St Wandrille, S. 8, weist darauf hin, daß erst Pippin 751 die Immunität wieder bestätigt.

37 Vgl. Gesta sanctorum Patrum Fontanellensis coenobii, ed. Lohier/Laporte, S. 43, Anm. 103. Cap. V,1: In seinem ersten Abtsjahr sei Papst Gregor gestorben, dem ein anderer Gregor nachfolgte. Im selben Jahr habe sich Karl gegen die Gascogne und den dortigen Prinzen Eudo gewandt. Raganfred sei nach vierzehn Jahren Tyrannei gestorben. Beda habe seine Kirchengeschichte verfaßt; in diesem Jahr wenigstens ende das Werk. Dann wird eine Urkunde zitiert (cap. V,2): Lando habe von Karl das Privileg der dauernden Immunität erhalten. Er stehe unter besonderem Schutz des Fürsten. Cap. V,3: Im zweiten Jahr seiner Herrschaft, dem Jahr 732, habe Eudo, Herzog der Aquitanier, weil er sich in der Verteidigung gegen Karl schwach fühlte, die Sarazenen zur Hilfe gerufen. Diese seien dann bis Bordeaux gezogen. Dort brannten sie Kirchen nieder, töteten Christen, rückten weiter bis Poitiers vor, brannten die Kiche von St-Hilaire nieder und planten auch, die Kirche des hl. Martin zu unterwerfen. Doch Karl gelang es, sie erfolgreich zu vertreiben. Lando habe Fontanelle drei Jahre geleitet, starb an einem 16. Januar und wurde in der Peterskirche von Fontanelle bestattet. - Zu Lando vgl. schon Sснміdт, Trier und Reims, S. 50 f. Er denkt auch an eine Parallelbesetzung von Milo und Lando.

38 Vgl. dazu schon oben S. 73 u. Anm. 20 sowie unten Kap. D.IV.6.c., Anm. 426. - Lando als Chorbischof sieht auch Schenk zu Schweinsberg, Reims, S. 168. 
Verwechslung mit einem anderen Lando, der in Reims im 7. Jahrhundert Bischof war $?^{39}$ Die Quelle bleibt schwierig. Doch sollte man ihr durchaus einige zuverlässige Informationen zubilligen. Schließlich bietet sie den einzigen stillen Hinweis auf den Verbleib des Sohnes des 751 abgesetzen letzten Merowingerkönigs, Childerichs III., mit Namen Theuderich. Theuderich wurde nämlich in Fontanelle ein Jahr nach seinem Vater inhaftiert. ${ }^{40}$

In der Vita des Abtes Benignus (710-724) wird schließlich auch ein Bischof Milo als Teilnehmer einer Versammlung Karl Martells von 722/3 erwähnt, was auf einer Urkunde beruhen dürfte. Allerdings bleibt sein Bischofssitz ungenannt. ${ }^{41}$ Auch hierauf stützt die Forschung ihre Datierung des Episkopats unseres Milo. ${ }^{42}$ Doch ist er tatsächlich gemeint? Könnte dieser Milo nicht auch ein anderes Bistum vertreten? Wenn der in den Gesta genannte Lando tatsächlich bis $733 / 5$ als Bischof von Reims amtiert haben sollte - was nicht unproblematisch ist - und Abel spätestens 744 dort eingesetzt wurde, dann blieben für Milo allenfalls die dazwischenliegenden rund 10 Jahre oder die Zeit nach Abels

39 Vgl. zu diesem Lando Duchesne, Fastes 3, S. 84. Flodoard II,6, ed. Stratmann, S. $147 \mathrm{f}$.

40 Vgl. Gesta sanctorum Patrum Fontanellensis coenobii cap. X,4, ed. Lohier/Laporte, S. 77. Chronique, ed. Pradié, S. 217. - Noch ein weiteres fällt auf: Die Forschung hat vermutet, daß Milo aufgrund seines Namens zur sog. Familie der, Widonen-Lambertiner-Miloniden' gehörte. Das einzige scheinbar sichere Indiz dafür ist allerdings die oben erwähnte Urkunde Karls des Großen für Mettlach (vgl. dazu oben Kap. C.II.3., aber auch Anm. 15, sowie ausführlich unten Kap. D.IV.6.). Nun finden sich zahlreiche Namen dieser Familie in der Überlieferung von St-Wandrille. So hieß der zweite Abt des Klosters Lambert (vgl. Vita Lantberti, ed. Levison, S. 606-612). In den Gesta finden sich ferner Angaben über einen Klausner Milo (vgl. Gesta sanctorum Patrum Fontanellensis coenobii cap. III,2, ed. Lohier/Laporte, S. 25-27; vgl. dazu Chronique, ed. Pradié, S. 207) und einen Abt Wido (von St-Wandrille und St-Vaast, 738 bis etwa 742/ 5) (vgl. Gesta sanctorum Patrum Fontanellensis coenobii cap. VII, ed. Lohier/Laporte, S. 56-58; vgl. dazu Chronique, ed. Pradié, S. 214). Dieser Wido sei ein ausgesprochen weltlicher Abt gewesen, der Jagd nicht abgeneigt. Eine Verschwörung gegen Karl Martell habe ihn schließlich das Leben gekostet. Die Vita beruft sich dazu auf die angebliche, mündliche Tradition eines Augenzeugen. Doch klingen die Vorwürfe wie die, die gegen Milo erhoben wurden. Wurden etwa mündliche Überlieferungen über Familienangehörige der Widonen-Sippe vermischt und schließlich Milo vorgeworfen? Mit welchen Traditionen hat man zu rechnen? - Vgl. zu den Angehörigen dieser Sippe auch unten Kap. D.IV.6.d., mit weiteren Belegen.

41 Vgl. Gesta sanctorum Patrum Fontanellensis coenobii cap. III,5, ed. Lohier/Laporte, S. 32 f., hier S. 33: In quo conuentu interfuerunt hi episcopi: Ebbo, Haldoinus, et Milo, [...]. Celebrata est haec euindicatio anno III regnante Theoderico iuniore rege, XIIII $\mathrm{Ka}$ lendas Augusti, Tulbiaco castro. - Eine nachträgliche Interpolation Milos läßt sich ebensowenig ausschließen, berücksichtigt man die weiteren Überlegungen dieses Kapitels.

42 Vgl. u. a. Anton, Trier im frühen Mittelalter, S. 62 f., sowie nochmals oben S. 68 f. u. Anm. 10-14. 
Letztnennung 746/7, hält man nicht weiter an der Lösung des Chorbischofs fest. ${ }^{43}$ Der oder die Verfasser der Gesta fanden sich jedenfalls in der Chronologie nicht mehr ganz zurecht.

\section{Der interpolierte Brief Papst Hadrians I. an Bischof Tilpin (JE †2411)}

Kehren wir nun zurück zur Überlieferung in Trier und Reims. Um es gleich vorweg zu nehmen: In Trier finden sich im 9. Jahrhundert keine Quellen, die Milo auch nur erwähnen. Dafür wird nun in den Reimser Texten ein geradezu miserables Bild Milos aufgebaut. Am Anfang steht dabei der folgende Text, der erst in der Mitte des Jahrhunderts entstand, auch wenn er selbst doch weitaus früher zu datieren scheint. Es handelt sich um den - schon erwähnten - vorgeblichen Brief des Papstes Hadrian I. (772-795) (JE †2411) an Bischof Tilpin von Reims (ca. 748/9 o. 751/4-794), den JAFFÉ zum Jahr 775 setzt, der aber nähme man ihn als zeitgenössisches Dokument ernst - spätestens bis 791

43 Vgl. dazu oben S. 73. - Das einzige Vorbild für eine Bistumshäufung bot der karolingische Bischof Hugo ( $†$ ca. 730 ?), der von Karl Martell über mehrere Bistümer (Rouen, Bayeux und Paris) eingesetzt worden sein soll. Er geht in den Gesta gleichsam Lando voraus. - Griff Hinkmar auf ihn als Vorlage für Milo zurück? Eine genauere Prüfung der Handschriften wäre dazu sicher noch erforderlich. Zu Hugo vgl. Große, Hugo. Hugo soll von Karl Martell nach dessen Sieg über Raganfred als Bischof in den drei genannten Bistümern eingesetzt worden sein. Sein Name wird auch auf den Bischofslisten von Lisieux und Avranches genannt. Er war Abt in Jumièges und Fontanelle. Vgl. die Vita sancti Hugonis, in: MPL 166, Sp. 1163-1172. Straeten, Vie inédite de S. Hugues, wo auch eine Einordnung der Quellen erfolgt. - Dabei könnte es sich allerdings auch um spätere Projektionen handeln. Für Trier ergeben sich zudem andere Probleme, wie wir noch sehen werden. - Vgl. ferner Semmler, Sukzessionskrise, S. 2, 19 f., 29-31, 33. Felten, Laienäbte, S. 120 f. - Insgesamt ist bei Hugo Vorsicht geboten. Eine Überprüfung gerade der zeitgenössischen Quellen erweist sich als dringend erforderlich. Die ersten wesentlichen Belege zu Hugos Leben setzten nämlich erst im 9. Jahrhundert ein. Schenk zu Schweinsberg, Reims, S. 167, möchte Lando gar nicht als Reimser Bischof anerkennen. - Ein Reimser Bischof Lando erscheint schließlich auch in der Vita Dagoberts III. (711-715/6), deren Datierung allerdings zwischen der Herrschaftszeit Karls des Kahlen $(\dagger 877)$ und dem 12. Jahrhundert variiert. Sie berichtet, daß Dagobert benedictionem adeptus est regiae dignitatis ab archipresule sedis Remensium nomine Landone. Auch wenn Lando zu dieser Zeit das Amt kaum innegehabt haben kann und auch der Titel des Erzbischofs ein Anachronismus ist, verwundert es dennoch, daß dieser Name noch erinnert wird. Vgl. dazu Vita Dagoberti III regis Francorum cap. 5, ed. KRusCH, S. 509 u. 515, Z. 23, wo Krusch auch der Datierung nachgeht. Die Vita setze sich aber überwiegend aus Fälschungen zusammen. Dem Schreiber der Vita sei die Reimser Chronologie nur in groben Zügen bekannt gewesen. - Insgesamt mutet die Quelle wie eine nachträgliche Legitimation von Reimser Salbungsrechten für fränkische Könige schon im frühen 8. Jahrhundert an. 
verfaßt sein müßte. ${ }^{44}$ Überliefert ist der Text am vollständigsten - jedoch in einzelne Fragmente zerlegt - in der Kirchengeschichte des Reimser Archivars Flodoard in der Mitte des 10. Jahrhunderts, der die Bestände und Dokumente seines Archivs hierin von der Reimser Frühzeit an systematisch zusammenzutragen und in einzelnen Büchern und Kapiteln zu ordnen versuchte. Dabei war er jedoch - schon wegen der zeitlichen Distanz - nicht immer in der Lage, den genauen Entstehungszusammenhang seines Materials und dessen Echtheit einzuordnen, weshalb ihm verständlicherweise einige Fehler unterliefen. ${ }^{45}$

In diesem Brief verleiht Papst Hadrian Bischof Tilpin das Pallium, bestärkt die Reimser Metropolitanrechte und privilegiert die Reimser Kirche, um damit die erneute Entfremdung von Reimser Kirchengut zu verhindern, die zuvor erfolgt sei. Dieser Brief ist schon seit vielen Jahren als Konstruktion bzw. Interpolation Hinkmars von Reims wohl von 852 bekannt. Emil LesNe hat dies durch den Vergleich mit weiteren Schriften Hinkmars und auch anderen im Brief verwendeten Texten überzeugend nachgewiesen. Insgesamt könne man nämlich seit etwa 852 Versuche Hinkmars feststellen, ein päpstliches Schutzprivileg für die Reimser Kirche zu erstreiten, das sich in ähnlicher Form im Brief finde. So projizierte der inserierte Briefteil dieses Privileg in die Zeit Tilpins zurück, obwohl es da noch gar nicht existierte. Auch die darin für das frühe 8. Jahrhundert beschriebenen Metropoliten sind ein Anachronismus, weil sich wie erwähnt - die Metropolitanverfassung erst gegen Ende des 8. Jahrhunderts durchsetzte. ${ }^{46}$ Die wohl tatsächlich echte Vorlage des Hadrian-Briefes dient als

44 Zur Datierung vgl. JE $† 2411$, S. 293. Sснміdт, Trier und Reims, S. 62, bemerkt, daß der darin erwähnte Weomad bis zu seinem Tode 791 einfacher Bischof geblieben ist. OexLe, Arnulf, S. 341, hält Metropolitanrechte Weomads aufgrund von DKarol. I 148 aber für möglich. - In jedem Fall müßte der Brief bis zum Tod Weomads abgefaßt sein. Zu Weomad vgl. oben Anm. 22 u. 71. - Zum Brief vgl. auch oben Kap. B.IV. bei Anm. $94 \mathrm{ff}$.

45 Vgl. die Fragmente bei Flodoard II,13, 16 f., S. 162 f., 166-169, und die Gesamtedition bei LesNe, Lettre, S. 349-351. Zu Flodoard und dessen Arbeitsweise vgl. Flodoard, ed. Stratmann, S. 1-31. Zimmermann, Regestentechnik. Sot, Flodoard. - Teile des Briefes werden aber schon Ende des Jahrhunderts in der noch zu diskutierenden Vita Rigoberti zitiert. Vgl. unten S. 97, bes. Anm. 91.

46 Vgl. Lesne, Lettre, S. 349-351, wo er den genauen Nachweis über verwendete Texte bzw. Übereinstimmungen mit späteren Schriften nachweist. Auch die Pseudoisidorischen Dekretalen fließen wohl ein. - Vgl. ferner ebd., S. 389-413. Erste Spuren fänden sich in seinem Schreiben an Leo IV. wohl um 852, in dem Hinkmar Privilegien für den Reimser Sitz erbittet und sich auf einen Primat von Reims bezieht. Vgl. dazu Schrörs, Hinkmar, S. 521 f., Reg. 53 u. S. 70 f. Flodoard III,10, ed. Stratmann, S. 207, Z. 3-8 (= MGH Epp. 8/1, ed. Perels, Nr. 62, S. 34): Leo antwortet Hinkmar auf seine Überlegungen zu einem Reimser Primat. Item in eadem de privilegiis huius Remensis ecclesie, que habuit ab initio, quo privilegia sedes habere ceperunt, et quia Remorum episcopus primas inter primates semper et unus de primis Gallie primatibus extitit nec alium se potiorem preter apostolicum presulem habuit, ut scilicet ea, que tanto tempore ab anteces- 
Anfang und Ende des Textes, dessen Mitte das lange Insert bildet. Im echten Teil bittet der Papst Tilpin um ein Gutachten über den Lebenswandel Luls von Mainz, der das Pallium erhalten sollte. Flodoard allerdings erkennt das später nicht mehr. ${ }^{47}$

Im Insert wird nun erstmals das negative Bild Milos in einem historischen Kontext verortet. Das Insert fingiert nämlich die Antwort des Papstes auf ein Schreiben Tilpins, das er nochmals referiert: Bei einem Streit unter den Franken soll „Erzbischof" Rigobert von Reims (wohl im frühen 8. Jahrhundert, ordnet man den Kontext recht ein) von seinem Sitz wider die Kanones abgesetzt und vertrieben worden sein, ohne ein Verbrechen begangen zu haben. Dies sei nicht auf der Grundlage eines bischöflichen Urteils geschehen, auch ohne Zustimmung des Papstes oder eine dortige Anfrage (diese Argumentation ist deutlich pseudoisidorisch ${ }^{48}$ ), sondern nur, weil er sich zunächst nicht mit der Partei desjenigen einigte, der später einen Teil von dessen Herrschaftsbereich in seinen Machtbereich aufnahm, in dem auch die Stadt Reims lag. - Ein Name wird dazu ausdrücklich nicht genannt. Auch scheint der Ungenannte nicht unmittelbar für die Absetzung verantwortlich, vielmehr seine Anhänger. ${ }^{49}$ - Und dieses Bistum erhielt - gegen Gott und dessen Autorität zugleich mit einem

soribus ipsius huic sedi sunt concessa et conservata, conservare et augmentare dignetur. - Der Brief datiert damit kurz nach dem Tod des ehemaligen Reimser Erzbischofs Ebo. - Das (wahrscheinlich von Hinkmar interpolierte) Privileg Papst Benedikts III. (855-858) und das von Papst Nikolaus I. (858-867) für die Reimser Kirche setzen Hinkmars Bemühungen fort. Vgl. zum manipulierten Benedikt-Privileg unten Anm. 47 unten. - Vgl. ferner zum Hadrian-Brief Nonn, Bild Karl Martells, S. 119 ff. Funrmann, Fälscher unter sich, S. 244, Anm. 35. Vgl. zur Fälschung ferner Stratmann, Verwalter. S. 48, 52, mit Literatur. Vgl. weiter Stratmann, Die Historia Remensis Ecclesiae, S. 118. Wattenbach-Levison-Löwe, Geschichtsquellen 5, S. 521, Anm. 109. Levison nehme eine Fälschung durch Ebo an. Schenk zu Schweinsberg, Reims, S. 175, hält die päpstliche Besitzbestätigung für eine Fälschung. - Vgl. Beispiele zum Ausbau der Metropolitanrechte bei Stratmann, Verwalter, S. $43 \mathrm{f}$ - - Zum Brief vgl. auch Schmidt, Trier und Reims, S. 38 f., zur Wiedererrichtung der Metropolen ebd., S. 58-77. OexLe, Arnulf, S. 328-345. - Vgl. zu den erwähnten Metropoliten auch unten Anm. 57.

47 Vgl. Flodoard II,17, ed. Stratmann, S. 169, Z. 26-35. Zumindest diese Passage scheint echt zu sein. Denn Lul verfaßte ein Glaubensbekenntnis, das für dieses kirchenrechtliche Verfahren notwendig war. Vgl. zu diesem Glaubensbekenntnis Schieffer, Angelsachsen und Franken, S. 152 ff. - Es bleibt im übrigen nicht das einzige Papstschreiben, das Hinkmar manipulierte. Vgl. dazu zusammenfassend Stratmann, Briefe an Hinkmar, S. 54-65. Hinkmar wurde unter anderem von Papst Nikolaus I. vorgeworfen, er habe das Benedikt-Privileg zur Bestätigung der Reimser Privilegien und der Beschlüsse der Synode von Soissons (853) gefälscht.

48 Vgl. dazu oben Kap. A.IV.

49 Gemeint ist aber wohl Karl Martell. Auch Nonn, Bild Karl Martells, S. 119 f., weist darauf hin, daß der Name Karl Martells hier nicht genannt wird. - Folgt man dem Analogie-Modell Hinkmars oben in Kap. B., könnte hiermit auch eine Kritik an Hinkmars 835 abgesetzten Vorgänger Ebo von Reims ausgedrückt bzw. von diesem auf Rigobert geschlossen worden sein. 
anderen Bistum und anderen Kirchen - Milo, ein zwar tonsurierter Kleriker, der aber nichts von der kirchlichen Ordnung wußte. Und andere Bistümer derselben Reimser Diözese wurden auf unterschiedliche Weise aufgeteilt. ${ }^{50}-$ Von Milo ist hier nur als Reimser, nicht aber als Trierer Bischof die Rede, wenn die Formulierung ihn tatsächlich überhaupt als Bischof kenntlich machen will.

Der Hadrian-Brief nimmt dann im gleich folgenden auch Bezug auf das (eigentlich ja 744) von Bonifatius geplante Pallium für Abel von Reims, das allerdings zur Zeit des Bonifatius und Fulrad verliehen worden sei. ${ }^{51}$ - Fulrad tritt aber erstmals etwa zwischen 749 und 751 († 784) als politischer Akteur in einer Quelle, nämlich den Reichsannalen, auf. Es liegt deshalb nahe zu vermuten, daß Hinkmar zu seinen Angaben deren Eintrag zur Königserhebung Pippins 751 benutzte, der beide Personen gemeinsam nennt. ${ }^{52}$ Die Stelle des Hadrian-Briefes läßt zudem deutlich die Verwendung der oben schon ausführlich genannten Bonifatiusbriefe erkennen. Hinkmar stützte sich neben den Reichsannalen auf eine Sammelhandschrift dieser Briefe. LESNE konnte bereits 1913 zeigen, daß der Verfasser daraus zitiert haben muß. ${ }^{53}$ Perels hat schließlich den genauen Nachweis über eine Reimser Bonifatiushandschrift der

50 Vgl. den Text bis hierher bei Flodoard II,13, ed. Stratmann, S. 162 f.: Tua fraternitas nobis retulit, quia faciente discordia inter Francos archiepiscopus Remensis nomine Rigobertus a sede contra canones deiectus et expulsus fuit sine ullo crimine et sine ullo episcoporum iuditio et sine ullo apostolice sedis consensu vel interrogatione, sed solummodo, quod antea non consensit in parte illius, qui postea partem de illo regno in sua potestate accepit, in qua parte Remensis civitatis est; et donatus atque magis usurpatus contra deum et eius auctoritatem fuit ille episcopatus, simul cum alio episcopatu et aliis ecclesiis a secularibus potestatibus Miloni cuidam, sola tonsura clerico, nichil sapienti de ordine ecclesiastico, et alii episcopatus de ipsa Remensi diocesi diverso modo essent divisi, et aliquid ex magna parte sine episcopis consistentes et ad alios metropolitanos episcopi et clerici ordinationes aliquando accipientes erant et refugia indebita habebant et a suis episcopis iudicari et distringi non sustinebant et clerici et sacerdotes et monachi et sanctimoniales sine lege ecclesiastica pro voluntate et licentia vivebant, [...].

51 Vgl. Flodoard II,16, ed. Stratmann, S. 167. Auch hier wird Reims bereits als Metropolitansitz bezeichnet: Sancte memorie Bonefacius archiepiscopus et legatus sancte Romane ecclesie et prefatus amabilissimus Fulradus, Francie archipresbiter, tempore antecessorum nostrorum Zacharie et Stephani successoris illius multum laboraverunt, ut bone memorie predecessor noster domnus Zacharias pallium archiepiscopo Remensi, Abel nomine, per deprecationem suprascripti Bonifacii transmitteret, [...]. - Zum Pallium für Abel vgl. nochmals oben Kap. C.II.2.

52 Vgl. den bekannten Eintrag der Ann. regn. Franc. ad. a. 749-750, ed. Kurze, S. 8 u. 10 .

53 Auch Lesne, Lettre, S. 397-399, fällt dies auf. Er bietet ein weiteres Beispiel von Parallelen zu den Bonifatiusbriefen (die Briefe des Zacharias an Wiza, Bischof von Büraburg, und Burchard von Würzburg - Epp. Bonifatii 52 f.) In seiner Edition des Hadrian-Briefes weist Lesne, Lettre, S. 349-351, die genaue Verwendung der Stellen aus den Bonifatiusbriefen nach. - Vgl. nochmals oben Kap. C.II.2. 
Klasse 2 geführt. ${ }^{54}$ Dann aber drängt sich der Gedanke auf, daß auch der im Hadrian-Brief erwähnte Milo über diese Handschrift von Hinkmar aufgegriffen wurde. Denn auf die schon erwähnte Passage zu „Milo und seinesgleichen“ mußte man zwangsläufig stoßen. Damit ist wohl davon auszugehen, daß Hinkmar aufgrund von mehreren in Reims vorliegenden Texten das Insert des Hadrian-Briefes entwarf, wobei es ihm - wie man schon an dieser Stelle sieht nicht gelang, die Chronologie korrekt wiederzugeben, wie wir sie heute zu kennen glauben. Die Textvorlagen machten es wohl kaum möglich.

Im Brief heißt es dann weiter, Abel habe sich nicht halten können, das Bistum Reims sei nach ihm viele Jahre vakant gewesen und der Reimser Besitz an Laien vergeben worden. Erst danach habe der neue Erzbischof Tilpin unter König Karlmann (768-771) und dann unter Karl dem Großen (768-814) die Güter zurückerworben. Es folgt das Privileg des Papstes zur Sicherung der Reimser Kirche. ${ }^{55}$ - Wie deckt sich das aber mit den schon oben angeführten weiteren Angaben zu Abel und auch Lando? Nach dem Hadrian-Brief war Reims nach Abel vakant. Die Reimser Usurpation durch Milo wäre dann vor Abel, also vor 744 anzunehmen. Vielleicht in den errechneten annähernd zehn Jahren zwischen Lando und Abel? Abels auch im Brief erwähnter Nachfolger Tilpin soll - folgt man der Forschung und diese folgt nun wiederum ganz anderen Angaben Hinkmars, als den hier aufgeführten - um 748/9 oder 751754 das dortige Amt übernommen haben. ${ }^{56}$ Das paßt aber alles überhaupt nicht

54 Vgl. Perels, Bonifatiusbriefe. Vgl. dazu auch Tangl, Studien, S. 72 ff. Ebd., S. 88, stellt er ein hohes Interesse für Bonifatius fest, vielleicht weil Ebo in dessen Diözese Mainz später zum Bischof von Hildesheim geweiht wurde.

55 Vgl. Flodoard II,16, ed. Stratmann, S. 167: [...] Abel nomine, per deprecationem suprascripti Bonifacii transmitteret, quod ab illo constitutus fuit, sed ibi permanere permissus non fuit, sed magis contra deum eiectus est et Remensis ecclesia per multa tempora et per multos annos sine episcopo fuit et res ecclesie de illo episcopatu ablate sunt et per laicos divise sunt, sicut et de aliis episcopatibus, maxime autem de Remensi metropolitana civitate.

56 Hier seien kurz die wesentlichen Ergebnisse dazu aus Kap. B.IV. u. B.V. zusammengefaßt: Das Datum berechnet sich nämlich überwiegend durch Angaben bei Hinkmar selbst. Bisher hat man nämlich - auf der Basis seines Textes über die Villa Neuilly - mit einem Tod des Bischofs 23 Jahre nach einer für 771 angenommenen Schenkung Karlmanns gerechnet. Todesjahr wäre dann 794. Das Epitaph an Tilpins Grab, das Hinkmar selbst verfaßte, liefert keine Angaben dazu. Es nennt als Todestag den 2. September und eine Amtszeit von quadragenis ast amplius annis, 40 und mehr Jahren. Er wußte es also selbst nicht genau oder schuldete die Angabe dem Versmaß. Vgl. Flodoard II,17, ed. Stratmann, S. 171, Z. 16-25, zur Grabinschrift. Mordek, Rechtsstreit, S. 103, Anm. 66, der den Text zur Villa edierte, erweckt gar den Eindruck, das Epitaph liefere das Todesjahr. - Flodoard dagegen gibt 47 Jahre an. Vgl. Flodoard II,17, ed. STRAтMANN, S. 171, Z. 13 f.: Qui presul defunctus est anno sui episcopatus XLVII. - Erstaunlicherweise erscheint Tilpin aber nicht beim Gebetsbund von Attigny 762. Vgl. Concilium Attiniacense 762 vel 760-762, ed. Werminghoff, S. 72 f. Vgl. dazu Schmid/ Oexle, Attigny. Trat er sein Amt also erst danach an? Die einzige zeitgenössische, zu 
zur inneren Chronologie des Briefes und der bisher diskutierten Quellen sowie zu den von der Forschung rekonstruierten Episkopatsdaten Milos: 722/3-761/ 2. Nach denen käme es nämlich zu einer Überschneidung bei der Besetzung Reims' durch Milo und dem dortigen Episkopat Tilpins. Die genannte lange Vakanz hat die Forschung nie berücksichtigt. Wären aber diese errechneten Amtsdaten Tilpins korrekt und damit das dann mögliche Jahr 748, dann könnte man bei einem 747 noch amtierenden Abel sogar von einer problemlosen Bistumsübergabe ausgehen. Folgt man aber dem Hadrian-Brief, ist Milos Anwesenheit in Reims nach Abel sicher auszuschließen. Das Bild der Forschung ist also nicht stimmig. Was aber geschah tatsächlich in Reims? Der Brief schreibt aus der Perspektive von 852, also über 100 Jahre nach den in ihm genannten Ereignissen und damit nach dem „floating gap“. Er bietet nicht nur die erste ausführlichere Quelle zu Milo, sondern ebenso zu den darin erwähnten Reimser Bischöfen Rigobert und Tilpin. Woher aber verfügte Hinkmar über diese Informationen?

Schon Lesne fiel auf, daß Hinkmar den interpolierten Brief als Argumentationshilfe gegen seinen König Karl den Kahlen ( $†$ 877) zur Restitution von verlorenem Reimser Kirchengut nutzte. Ludwig der Fromme (813/4-840) hatte seinen ehemaligen Vertrauten, den Reimser Erzbischof Ebo (seit 816/7), der sich gegen ihn mitverschworen hatte, 835 abgesetzt. Und seit dieser Zeit mit einer kurzen Unterbrechung in den karolingischen Bruderkriegen - war dieses Bistum vakant und wurde nur extern verwaltet. ${ }^{57}$ Man bediente sich in den Bruderkriegen dann der Kirchengüter, um die eigenen Gefolgsleute be-

Tilpin überlieferte Quelle weist ihn auf der Römischen Synode von 769 nach. Vgl. Concilium Romanum, ed. Werminghoff, S. 74-92, bes. S. 75, Z. 13 u. S. 80, Z. 11 f. - Erst die vermutlich im 12. Jahrhundert im Kloster Steinfeld (gegr. 10./11. Jahrhundert) verfaßten, aber vielleicht auf zeitgenössischen Notizen beruhenden Historiae Francorum Steinveldenes, ed. WAITZ, S. 726-729, hier S. 728, notieren deutlich: Anno dominicae incarnationis 794, indictione 2, anno 47. sui episcopatus, 4. Nonas Septembris defunctus est Tilpinus archiepiscopus Remensis. Es wäre allerdings durchaus zu überlegen, ob dieser Eintrag auf einer unabhängigen Vorlage beruhte oder aufgrund von Flodoard und Hinkmar errechnet wurde. - Merkwürdigerweise findet sich in der Handschrift C3 der Reichsannalen aus St-Omer im 10. Jahrhundert zum Jahr 789 der Zusatz: Hoc vero anno, ut computatum est, depositio fuit Tilpini episcopi IIII. Non. Septembr. Vgl. Ann. regn. Franc., ed. Kurze, S. XI u. 84. Den Hinweis dazu verdanke ich Herrn Dr. Matthias Tischler (Frankfurt a. M.). - Die Bistumsdaten bedürfen also dringend der Überprüfung. - Die wesentlichen Quellenstellen und die bisherige Forschungsmeinung finden sich auch zusammengefaßt bei SCHenk zu Schweinsberg, Reims, S. 172-176. Bauer, Tilpin. Herbers, Turpin. Zu Tilpin vgl. insgesamt auch nochmals Flodoard II,17, ed. Stratmann, S. 168-171, bes. S. 168, Anm. 2; S. 171, Anm. 57. - Insgesamt wäre es also auch denkbar, daß Hinkmars Angaben zu Tilpin in seiner Denkschrift zu Rothad von Soissons zutreffen und Tilpin erst sehr spät zu seinem Amt gekommen ist. Vgl. dazu unten S. 88-90 u. Anm. 69-72.

57 Vgl. ausführlich dazu Flodoard II,19-III,5, ed. Stratmann, S. 175-197. 
lohnen zu können. Als Hinkmar das Erzbistum 845 übernahm, war es eines seiner wesentlichen Anliegen, den verlorenen Besitz zurückzuerlangen. Jedes Mittel schien ihm dazu recht, wie er überhaupt in seiner bis 882 währenden Amtszeit oft zur Manipulation von Texten griff, um seine politischen Ziele zu verfolgen, und sicher zu einem der einflußreichsten Kirchenmänner überhaupt und Karls des Kahlen im besonderen gehörte. ${ }^{58}$ So entwirft er im Hadrian-Brief ein Gegenbild zu seiner eigenen Zeit. Rigobert verliert seine Ämter wie Ebo. Das Bistum wird fremdverwaltet. Und erst ein neuer Bischof kann beim König die Restitution der Kirchengüter durchsetzen: damals Tilpin, dann Hinkmar selbst. $^{59}$

\section{Die Visio Eucherii des Hinkmar von Reims}

Gleichzeitig, wenn auch noch nicht in diesem Brief, baute Hinkmar das Bild von Karl Martell als dem Enteigner von Kirchengut auf. Bis zu dieser Zeit war dessen Andenken nicht negativ konnotiert. Doch nun trat ein allmählicher Wandel ein. Während Karl im Hadrian-Brief nicht einmal namentlich begegnet - obwohl er mit dem großen Unbekannten gemeint sein könnte - wird er erstmals in der von Hinkmar überlieferten und wohl auch von ihm wenigstens teilweise verfaßten Visio Eucherii im Synodalprotokoll von Quierzy (November 858) als Kirchenräuber und -enteigner ausgemacht. Ulrich NonN hat dies ausführlich untersucht. ${ }^{60}$

Karl Martell hatte Bischof Eucherius von Orléans (717-738) bald nach seiner erfolgreichen Araberschlacht 732 aus seinem Bistum verbannt. 738 starb er in Klosterhaft. So berichtet es zumindest die nicht lange nach Eucherius' Tod verfaßte Vita. ${ }^{61}$ In der dann viel späteren Visio sah Bischof Eucherius in einer Vision Karl Martell für seinen Frevel entsetzliche Höllenqualen leiden. Aufgewacht möchte der Bischof, daß Bonifatius und Abt Fulrad von St-Denis - die hier schon wieder gemeinsam auftreten - das Geschaute an Karls Grab überprüfen. Man findet darin schließlich auch nicht dessen Körper, sondern einen

58 Man denke bei seinem umfangreichen Schriftgut nur an den Fürstenspiegel De ordine palatii und die Verfasserschaft der Annales Bertiniani über weite Jahre. Vgl. zu Hinkmar nochmals Schrörs, Hinkmar. Devisse, Hinkmar. Schieffer, Hinkmar. Stratmann, Verwalter. Fuhrmann, Fälscher unter sich. Wattenbach-Levison-Löwe, Geschichtsquellen 5, u. a. S. 503-505, 515-525, 536-539. Vgl. dazu die Schriften De ordine palatii, ed. Gross/Schieffer, sowie die Ann. Bert., ed. Waitz.

59 Vgl. dazu ähnlich auch LesNe, Lettre, S. 325-348.

60 Vgl. Nonn, Bild Karl Martells, der die Quellen zu Karl Martell chronologisch durchprüft.

61 Vgl. dazu Nonn, Bild Karl Martells, S. 77 u. 107, sowie die Vita Eucherii, ed. Levison. Wattenbach-Levison-Löwe, Geschichtsquellen 2, S. 168. Berschin, Biographie 2, S. 65 f. Vgl. dazu auch Schieffer, Karolinger, S. 46 f. Fried, Weg, S. 209. 
Drachen. Hinkmar will noch Augenzeugen dieses Ereignisses gekannt haben. Historisch ist der Inhalt schon aufgrund der Ungleichzeitigkeit der erwähnten Personen nicht haltbar. ${ }^{62}$

Die Eucherius-Vita oder das Wissen um Eucherius könnte Hinkmar allerdings nicht nur für die Visio eine Vorlage geboten haben. Ebenso kann man hierin bereits ein Vorbild für den aus seinem Bistum vertriebenen Rigobert erkennen. Aber auch die Bonifatiusbriefe dürften Hinkmar eine der Grundlagen für den Aufbau seines Karlsbildes geboten haben. Denn in Bonifatius' erstem Brief an den neuen Papst Zacharias I. vom Frühjahr 742 findet sich eine umfangreiche Beschreibung über den üblen Zustand der fränkischen Kirche des frühen 8. Jahrhunderts und die Vergabe von kirchlichen Ämtern an Laien etc. Damit beschreibt er die Zeit Karl Martells. Hinkmar zitiert dies - oft auch sinngemäß - immer wieder in seinen Texten, zum ersten Mal bereits im Hadrian-Brief, wo Milo genau in diesen Kontext eines Laien eingeordnet wird. ${ }^{63}$ All diese Quellen vermittelten Hinkmar eine ausgezeichnete Basis, auf der er sein Bild der Reimser Kirche im 8. Jahrhunder beschreiben und entwerfen konnte. Die Enteignungen, die Vertreibung, das weltliche Verhalten der Kleriker fand Hinkmar in ihnen bereits vor.

62 Vgl. Hinkmar, Visio Eucherii, ed. Hartmann, S. 414-417. Vgl. dazu auch Nonn, Bild Karl Martells, S. 106-114, zum Nachwirken. Wattenbach-Levison-Löwe, Geschichtsquellen 5, S. 519 f., wo noch weitere mögliche Visionen (die Visio Bernoldi sowie die Visio Raduini) angeführt werden, mit denen Hinkmar Einfluß auf das politische Geschehen zu nehmen versuchte. Schrörs, Hinkmar, S. 507 ff. - Zur Visio vgl. LEvison, Politik in den Jenseitvisionen, bes. S. 107 ff. Fuhrmann, Einfluß 1, S. 116. DinZelbacher, Vision, S. 58 u. 60. - Erstaunlicherweise erscheinen hier Bonifatius und ebenso Fulrad, dessen sich Hinkmar noch in weiteren seiner Texte bediente. - Und auch die Forschung glaubt nicht mehr an diese massive Form der Enteignungen von Kirchengut durch Karl Martell. Vgl. zu Karl Martell insgesamt die Sammelschrift Karl Martell in seiner Zeit, ed. JARnUt/Nonn/Richter; darin Überlegungen bei GEARY, Die Provence zur Zeit Karl Martells, S. 381-392, der die Projektion einer Enteignung Pippins III. auf die Zeit Karl Martells untersucht. - Zum Rahmen vgl. SEmmler, Sukzessionskrise, S. 1-36.

63 Vgl. Epp. Bonifatii 50, ed. TANGL, S. 80-86, hier S. 82 f., bes. S. 82: Franci enim, ut seniores dicunt, plus quam per tempus octuginta annorum synodum non fecerunt nec archiepiscopum habuerunt nec aeclesiae canonica iura alicubi fundabant vel renovabant. Modo autem maxima ex parte per civitates episcopales sedes tradite sunt laicis cupidis ad possidendum vel adulteratis clericis scortatoribus et publicanis seculariter ad perfruendum. Nam si per verbum vestrum hoc negotium duce rogante supradicto movere et incipere debeo, praeceptum et iudicium apostolicae sedis cum canonibus ęclesiasticis presto habere cupio. Vgl. dazu beispielsweise die anfangs erwähnte Denkschrift Hinkmars zu Rothad von Soissons von 863, in: MGH Epp. 8/1, ed. Perels, Nr. 160, S. 125, Z. 16-19, oder die Passage im Hadrian-Brief oben Anm. 50f., 55. 
4. Der Konflikt zwischen Reims und Trier im 9. Jahrhundert

Noch eine ganz andere Komponente könnte zudem beim Hadrian-Brief zu bedenken sein: LESNE fiel bereits eine mögliche Verbindung des inserierten Hadrian-Briefes mit den vom Trierer Erzbischof Thietgaud $(847-863, \dagger 868)$ erhobenen Primatsansprüchen gegenüber Reims auf. Doch verfolgte er dies nicht weiter. ${ }^{64}$ Thietgaud berief sich dabei offenbar auf die inzwischen in Umlauf gekommenen Pseudoisidorischen Fälschungen. Er griff hierzu wahrscheinlich die spätantike Notitia Galliarum wieder auf, ${ }^{65}$ in der die alte Provinz Gallia Belgica in zwei Metropolitanbezirke Belgica prima, Trier, und Belgica secunda, Reims, aufgeteilt ist. Trier als prima komme - so wohl Thietgauds Argumentation - damit auch der Primat über die gesamte Gallia und folglich auch über Reims zu. Es versteht sich, daß dies den Unmut Hinkmars erregen mußte, wie sich noch an einem Briefregest Flodoards nachvollziehen läßt. Genannt ist dort ein Schreiben Hinkmars an Thietgaud wegen dieses Themas, das die Forschung auf 852/3 datiert. Allerdings ist dies auch die einzige Quelle, in der Thietgauds Ansprüche explizit erkennbar sind. ${ }^{66}$ Könnte dieser Konflikt zwischen Trier und Reims nicht auch ein Gegenbild in der Absetzung Rigoberts und der Verwaltung Reims' durch den auswärtigen Milo im 8. Jahrhundert haben? Im Hadrian-Brief wäre es jedoch zunächst nur grob angedeutet.

64 Vgl. Lesne, Lettre, S. 396, 406 f. - Zu Thietgaud vgl. zusammenfassend Apsner, Hochund spätkarolingische Zeit, S. $267 \mathrm{ff}$. AnToN, Raumbestimmende Voraussetzungen, S. 182-185. Anton, Trier in der hohen und späten Karolingerzeit, S. 74 f., 77, 98 f., $101 \mathrm{f}$, , 104, 113. Herbers, Thietgaud. Bauer, Theutgaud, mit umfangreicher Literatur. Herbers, Leo IV., S. 341. Hartmann, Synoden, S. 274-284. Goerz, Regesten der Erzbischöfe von Trier, S. 1 f. - Vgl. dazu insgesamt auch SснміDт, Trier und Reims, S. 77 ff. Funrmann, Patriarchate II, S. 35 ff., bes. S. 37, Anm. 117, griff es erneut auf.

65 Vgl. Notitia Galliarum, ed. Mommsen. Vgl. dazu Mordek, Notitia. Duchesne, Fastes 3, S. 7 f. - Zum Wirken Pseudoisidors vgl. oben Kap. A.IV. Daß die Pseudoisidorischen Dekretalen nach Trier gelangten, verwundert nicht, wenn man bedenkt, daß Thietgauds Vorgänger Hetti u.a. ein Anhänger Kaiser Lothars I. war, in dessem politischen Umfeld die Dekretalen entstanden. Zu Hetti vgl. unten Kap. D.IV.3.

66 Vgl. Flodoard III,21, ed. Stratmann, S. 271, Z. 1 f.: Teutgaudio Treverensi de primatu, quem deferri ab eo debere scripserat ille sedi Trevirorum, insinuans id eidem sedi a sede Remorum numquam fuisse delatum et cetera (= MGH Epp. 8/1, ed. Perels, Nr. 58, S. 33). Vgl. dazu auch Schrörs, Hinkmar, S. 165 f. u. S. 519, Reg. 17, der auf 847 datiert. Devisse, Hincmar 1, S. 51, 369-386, 439-451 (insgesamt aber nicht immer zum Thema). - Die Literatur zum Trierer Primatsanspruch ist äußerst dürftig. Thietgauds Primatsanspruch ist nur durch dieses Flodoard-Regest bekannt und fußt wohl auf pseudoisidorischen Ideen. Vgl. Sснмidt, Trier und Reims, S. 81 f., 87 f. Fuhrmann, Patriarchate II, S. 12 ff., 35 ff. Lugge, Gallia, S. 183. Heydenreich, Trier, S. 113-134, hier S. 118. Fuhrmann, Einfluß 1, S. 48 f., 191, 197-210, bes. S. 199, auch mit der Datierung auf 852/3. Anton, Trier im frühen Mittelalter, S. 202. Anton, Trier in der hohen und späten Karolingerzeit, S. 110 f. ApsNer, Hoch- und spätkarolingische Zeit, S. $267 \mathrm{ff}$. 
In jedem Fall befand sich Hinkmar zunehmend in erbittertem Gegensatz zu Thietgaud. Dessen Absetzung und Exkommunikation $863 \mathrm{kam}$ ihm sicherlich gelegen. Thietgaud unterstützte nämlich den König des nördlichen Mittelreichs, Lothar II. (855-869), den Namensgeber des baldigen Lotharingien, gemeinsam mit dem Kölner Erzbischof Gunthar bei dessen Versuch, sich von seiner ersten Ehefrau Theutberga zu trennen. Der Verbindung ermangelte es an einem männlichen Nachfolger. So wollte Lothar seine Friedelfrau Waltrada heiraten, mit der er bereits einen Sohn, Hugo, hatte. Der Hergang soll hier nicht im einzelnen geschildert werden. Doch hatten Lothars Oheime, der Westfranke Karl der Kahle († 877), Hinkmars König, und der Ostfranke Ludwig der Deutsche ( $† 876)$, kein Interesse daran. Beide hofften bei Erbenlosigkeit Lothars auf die eigene Übernahme des Mittelreiches. Um diese Eheangelegenheiten kirchenrechtlich zu prüfen, fertigte Hinkmar - dazu wohl von Adligen sowie einigen Bischöfen aufgefordert - sogar eigens eines seiner Rechtsgutachten an. ${ }^{67}$ 863 schließlich wurden Thietgaud und Gunthar von Papst Nikolaus I. (858867) exkommuniziert, weil sie ihren König bei seinem Vorhaben ohne Rücksprache mit dem Papst unterstützten. Doch selbst die römische Absetzungssynode von 863 nennt Thietgaud noch mit dem Primas-Titel. Die Frage nach dem Primat muß also für den Reimser Erzbischof stets virulent geblieben sein. ${ }^{68}$

\section{Hinkmars Denkschrift von 863}

In diese Zeit gehört auch die oben schon zitierte Denkschrift zu Rothad II. von Soissons (832-862 u. 865-869) von Februar/März 863, für die Ernst Perels die Verfasserschaft Hinkmars von Reims gesichert hat. Sie beschäftigt sich ebenfalls überwiegend mit den Rechten des Metropoliten. Die Schrift lasse deutlich Hinkmars Arbeitsstil erkennen, der zahlreiche für ihn wichtige Textstellen des Kirchenrechts und aus historischen Quellen zusammentrage, um sie für seine Argumentation dienstbar zu machen. Auch wenn der Text nur in einer

67 Vgl. dazu Hinkmar, De divortio Lotharii regis, ed. BöHringer. Vgl. zusammenfassend zum Ehestreit mit den Hinweisen zur Literatur ebd., S. 1-20. Zur Schrift selbst vgl. ebd., S. 20 ff. Beim Werk handelt es sich um eine Auftragsarbeit; die Namen der Fragesteller werden jedoch verschwiegen. Abgefaßt wurde es wohl 860. Die Schrift, die nur in einer Handschrift überliefert ist, richtete sich zwar an alle Christen, verlor aber nach dem Tod Lothars II. ihren unmittelbaren Nutzen.

68 Vgl. dazu Schrörs, Hinkmar, S. 188-205. Hartmann, Synoden, S. 274-284. Fried, Weg, S. 398-400. Schieffer, Karolinger, S. 152-155. - Vgl. auch Hinkmars Überlegungen, einen Reimser Primat zu sichern, oben S. 90-92 u. Anm. 73-75. - Die Protokolle der Römischen Synode von 863 finden sich neben den Ann. Fuld. ad a. 863, ed. Kurze, S. 58-61, hier S. 59, auch in den Ann. Bert. ad a. 863, ed. Wartz, S. 6370, hier S. 64: Cap. 2. I... Theotgaudum Treverensem, primatem Belgicae provinciae, [...]. Vgl. dazu Staubach, Rex christianus 2, S. 172-181. 
einzigen fragmentarischen Handschrift überliefert ist, so diente er dem Reimser Erzbischof später immer wieder als Zitatfundgrube für weitere Schriften und Streitschriften. Diese Denkschrift fungierte offenbar als seine wesentliche Arbeitsgrundlage. ${ }^{69}$ Mehrere solcher zusammengetragener Quellen kann man auch im Kontext der Erwähnung Milos erkennen, die hier nochmals ausschnitthaft wiedergegeben werden soll:

Bonifatius sei die Vertretung des apostolischen Stuhles in den gallischen, belgischen und germanischen Provinzen übertragen worden, um die Einhaltung der Kanones beim Klerus zu überwachen. Er habe Grimo in Rouen und Hartbert in Sens ordiniert. In Reims und Trier jedoch, die der sich nicht als Kleriker verhaltende Milo innehatte, ließen sich die dort vorgesehenen Bischöfe nicht durchsetzen. Als später Weomad Trierer Bischof wurde, sei Reims dann längere Zeit vakant gewesen, weil Milo die dortigen Güter an seine Söhne und Anhänger verteilt habe. ${ }^{70}$

Es fällt sofort auf, daß sich Hinkmar hier erneut u.a. der Bonifatiusbriefe bediente. Allerdings geht die Darstellung weit über deren Inhalt hinaus. So erhält Bonifatius eine Art apostolisches Vikariat in der Gallia, Belgica und Germania. Seine Erzbistumspläne werden auch erwähnt. In diesem Zusammenhang treten wieder die Namen Grimo und Hartbert auf. Doch erstaunlicherweise kommen die für Reims möglichen Namen Rigobert (Lando mit einiger Vorsicht) und vor allem Abel, auf den Hinkmar schon aufgrund seiner Angaben im Hadrian-Brief zweifellos gestoßen sein muß, überhaupt nicht zur Sprache. Stattdessen erscheint Milo nun nicht nur als Verantwortlicher in Reims, sondern auch in Trier und das zur Zeit des Bonifatius. An beiden Orten habe es nämlich Probleme mit den dort vorgesehenen Bischofskandidaten gegeben. Erstmals wird Milo damit von Hinkmar überhaupt mit Trier in Verbindung gebracht und erhält nun noch ihn beerbende Söhne. Wie Milo nun in diese „Doppelposition“ gekommen ist, bleibt dagegen völlig offen. Vielleicht versucht Hinkmar damit, immanenten chronologischen und darstellerischen Schwierigkeiten auszuweichen, die sich ergäben, würde er Abel und die Um-

69 Vgl. dazu Hinkmar, Denkschrift, ed. Perels, S. 43-72. Vgl. zum gesamten Vorgang um Rothad II. von Soissons hier nur kurz Stratmann, Rothad II. Hartmann, Synoden, S. 313-316, mit der weiteren neueren Literatur. Zur Denkschrift vgl. auch oben Kap. A.I. sowie den Anfang von Kap. B.III.

70 Vgl. Hinkmar, Denkschrift cap. I,8, ed. Perels, S. 77 f. (= MGH Epp. 8/1, ed. Perels, Nr. 160, S. 125 f.). Vgl. zum Text und einer vollständigen deutschen Übersetzung auch oben Kap. A.I. u. Anm. 3. - Das Jahr 862 bot für Hinkmar noch eine ganz andere Besonderheit. Denn der Neubau der Reimser Kathedrale wurde in Gegenwart Karls des Kahlen geweiht. Vgl. dazu Ann. Bert. ad a. 862, ed. Wartz, S. 60: Hincmarus Remorum episcopus, veniente Karolo rege in eandem civitatem, accitis comprovincialibus suis episcopis, matrem ecclesiam ipsius provinciae in honore sanctae Mariae, sicut et antiqua fuerat sacrata, venerabiliter dedicat. 
stände seiner Einsetzung hier nennen. Daß es Chronologieprobleme gibt zumindest für den auf der Basis einer umfangreicheren Datenlage kritisch prüfenden Historiker -, zeigt die Bemerkung zu Weomad. Denn seit seinem Amtsantritt, also dann wohl nach Milos Tod, sei Reims für einige Zeit vakant gewesen. Weomad aber ist frühestens seit 762 als Trierer Bischof nachweisbar. ${ }^{71}$ Und zu dieser Zeit müßte in Reims längst - folgt man wieder der gängigen Forschungsmeinung - Tilpin eingesetzt gewesen sein. Tilpin wird aber in der Denkschrift selbst erst wesentlich später eingeführt, eben nach der Vakanzzeit. Diese bereits von Hinkmar im Hadrian-Brief erwähnte, längere und wohl bischoflose Phase in Reims wird nun plötzlich in die Zeit nach Milo verschoben. Im Hadrian-Brief schloß sie sich aber nach Abel an. Ganz undeutlich verbindet diese Quelle damit bereits Milos - noch im Hadrian-Brief erwähnte - Herrschaft in Reims vor Abel mit der Vakanz nach Abel. Und eben nur durch das Auslassen Abels wird dieses neue Bild glaubwürdig. Die Verbindung Milos mit Trier und die Nennung Weomads ermöglichen es dann zusätzlich, die immer noch erwähnte Reimser Vakanz zeitlich weiter nach hinten zu verschieben. ${ }^{72}$

\section{Hinkmars Schreiben an Papst Nikolaus I. von 864}

$\mathrm{Da}$ diese vergangenen Ereignisse zunächst in Reims und dem in der Denkschrift eingeführten Trier in einer gewissen Nähe zu Hinkmars eigener Zeit und vielleicht sogar auch zum Primatsstreit zwischen Reims und Trier stehen könnten, scheint ein Schreiben Hinkmars an Papst Nikolaus I. (858-867) aus dem Jahr 864 wahrscheinlich zu machen. Einige Bemerkungen zu Milo ergänzen dabei seine bisherigen Aussagen:

Es habe niemals einen Primat gegeben, außer als zur Zeit des Fürsten Karl der Reimser Bischof ohne jegliches Verbrechen gewaltsam vom Tyrannen Milo vertrieben worden sei und der apostolische Legat Bonifatius die Verwaltung des vakanten Bistums, aber auch der Trierer Kirche übertragen erhielt. Zwischen der Trierer und Reimser Kirche, nur diese beiden bildeten die Belgica, habe es immer eine Unterscheidung gegeben, nach kirchlichen Schriften wie nach alter Gewohnheit. Nämlich die, daß nicht der Ort - gemeint ist wohl der von Thietgaud postulierte Vorrang der Belgica I, dessen Metropole Trier war -,

71 Vgl. dazu Bauer, Weomad, Sp. 767-772, bes. Sp. 767 f. Anton, Trier vom Beginn des 6. bis zum Ende des 8. Jahrhunderts, S. 50, $60 \mathrm{f}$. ANTON, Trier in der hohen und späten Karolingerzeit, S. 71, 94-96, 108 f., 112 f., 133. Anton, Raumbestimmende Voraussetzungen, S. 166, 172, 179, 193. BAUER, Spätmerowingische Zeit, S. 222, 236 f., $245-$ 251, 253. Bauer, Verehrung heiliger Trierer Bischöfe, S. 400. - Weomad erscheint erstmals als Zeuge einer Urkunde Pippins III. für Prüm vom 13. August 762. Vgl. dazu DKarol. I 16, S. 21-25, hier S. 24, Z. 43.

72 Vgl. dazu oben S. 74, 79 f. u. Anm. 22 u. 44. 
sondern die jeweils längere Ordination den Vorrang der entsprechenden Metropole in der Belgica bestimme. ${ }^{73}$

Nun ergibt sich erneut ein völlig anderes Bild. Auch diesmal verschweigt Hinkmar die Namen der älteren Reimser Bischöfe. Erstmals fällt in Verbindung mit einem lediglich als Tyrann bezeichneten Milo nun auch der Karl Martells. Dies könnte durchaus mit Hinkmars Versuch, das Karlsbild zu verdunkeln, zusammenhängen. Chronologische Angaben fehlen gänzlich. Zum ersten Mal aber wird ein direkter Bezug zwischen Milo und Hinkmars Konflikt mit Thietgaud hergestellt. Bonifatius habe nämlich beide Teile der Kirchenprovinz Belgica gemeinsam verwaltet. Das müßte aber bedeuten, daß Milo dann noch unter Bonifatius (also bis spätestens zu dessen Tod 754) seinen Einfluß sowohl in Reims wie in Trier verlor. Auch hier stimmen Hinkmars Angaben mit der Chronologie des heutigen Historikers nicht überein. Die Frage bleibt, ob sich Hinkmar in der Nachfolge des Bonifatius als Verwalter der gesamten Belgica betrachtete. In jedem Fall sah er sich als der zeitlich vor Thietgaud ordinierte Metropolit und damit als eigentlicher Primas der Provinz an. Letztlich vereinfachte jedoch Thietgauds Absetzung 863 die Situation erheblich. Im nachhinein ließ sich also leichter argumentieren. Trier blieb denn auch bis zur Einsetzung Erzbischof Bertolfs im Jahr 870 vakant. $^{74}$

Seine Rolle als einziger Metropolit der Belgica nach 863 und selbstverstandener Primas setzte Hinkmar dann auch bei der Erhebung Karls des Kahlen 869 zum König über das Mittelreich Lotharingien in Metz ein und benutzte sie als Rechtfertigung für sein Handeln als dortiger Zelebrant. Im berühmten Metzer Ordo begründet er seine herausragende Rolle unter Wiederaufnahme seines Briefes an Nikolaus folgendermaßen:

„Damit nicht etwa jemand glaubt, ich und die ehrwürdigen Mitbischöfe unseres Sprengels handeln unziemlich und anmaßlich, da wir uns in die Regelung und die Verhältnisse dieses Sprengels einmischen, so möge er wissen, daß wir nicht gegen die

73 Vgl. dazu Flodoard III,13, ed. Stratmann, S. 233, Z. 21-28 (= MGH Epp. 8/1, ed. Perels, Nr. 169, S. 144-163, hier S. 157): Que numquam excepto Romano pontifice primatem habuit, nisi quamdiu eiecto sine ullo crimine ab ea suo pontifice violentia tyranni Milonis tempore Karoli principis pastore vacans Bonifacio apostolice sedis legato aliquandiu, sicut et ecclesia Trevirensis, commissa fuit. Inter quas, Remensem scilicet et Trevirensem ecclesiam - has enim duas tantum provincias Belgica regio habet -, hec semper distinctio fuit, sicut in ecclesiasticis monimentis invenimus et vetustissimam consuetudinem semper obtinnuisse comperimus, ut isdem episcopus non loci, sed dignitate ordinis prior secundam sacras regulas haberetur, qui foret in qualibet istarum ecclesiarum metropoli antea ordinatus. Schrörs, Hinkmar, S. 530, Reg. 174. - Der Brief beschäftigt sich u. a. auch mit Rothad von Soissons.

$74 \mathrm{Zu}$ diesem Bischof und seiner Einsetzung vgl. Goerz, Regesten der Erzbischöfe von Trier, S. 2. Duchesne, Fastes 3, S. 43 f. Zuletzt Anton, Trier in der hohen und späten Karolingerzeit, S. 77-79, 99, $101 \mathrm{f}$. ApsNer, Hoch- und spätkarolingische Zeit, S. $271 \mathrm{ff}$. 
heiligen Canones handeln, weil die Kirchen von Reims und Trier in diesem belgischen Lande mit den ihnen zugewiesenen Kirchen als Schwestern und Angehörige des alten Sprengels gelten, wie die kirchliche Autorität und die Sitte seit ältesten Zeiten beweisen, und daß sie deswegen mit allgemeiner Zustimmung die Synodalgerichte abhalten und einträchtig das bewahren sollen, was von den heiligen Vätern festgesetzt worden, unter Beobachtung der Sonderbestimmung, daß wer von den Bischöfen von Reims und Trier zuerst geweiht wurde, auch den Vorrang haben soll." "75

\section{Hinkmars Brief an seinen Neffen Hinkmar von Laon von 869}

Während des schwelenden Konfliktes mit seinem Neffen Hinkmar von Laon (Bischof 858-871, † 879) in den Jahren 868-871 um Laoner Kirchengut griff der Reimser Metropolit in einem Brief von 869 an seinen Suffragan einmal mehr auf die Reimser Bistumsgeschichte des frühen 8. Jahrhunderts als Argumentationshilfe zurück. $^{76}$ Er schrieb diesmal jedoch erstaunlicherweise vom Reimser Bischof Rigobert, der gewaltsam von seinem Sitz vertrieben worden sei und auf seinem Eigentum nicht weit von der Stadt viele Jahre unter großem Mangel gelebt habe. Anderen Bischöfen sei zu dieser Zeit ein ähnliches Schicksal widerfahren. Gerade hier fällt besonders die inhaltliche Parallele zum erwähnten Bericht der Vita Eucherii auf. ${ }^{77}$ Die Angabe bleibt bei Hinkmar von Reims singulär. Denn jetzt werden weder die weiteren Reimser Bischöfe noch Milo in diesem Zusammenhang erwähnt. Scheut Hinkmar hier, präziser zu werden und den offenkundigen Widerspruch zu seinem inzwischen entworfenen Milobild

75 Vgl. Jahrbücher von St. Bertin, ed. Rau, S. 197. Vgl. dazu Ann. Bert. ad a. 869, ed. WAITZ, S. 103: Ne alicui forte videatur, incongrue ac praesumptiose me ac provinciae nostrae venerabiles coepiscopos facere, quoniam de altera provincia ordinationi et causis huius provinciae nos immiscemus, sciat, nos contra canones sacros non agere, quoniam Remensis et Treverensis ecclesiae in hac regione Belgica cum sibi commissis ecclesiis sorores et comprovinciales habentur, sicut auctoritas ecclesiastica et antiquissima demonstrat consuetudo, ac per hoc unanimi consensu et synodalia iudicia exercere et quae a sanctis patribus constituta sunt debent concorditer custodire, hac privilegii conditione servata, ut, qui prior de Remensi et Treverensi episcopo fuerit ordinatus, prior etiam habeatur.

76 Vgl. zu diesem Konflikt Schrörs, Hinkmar, S. 315-353. Große, Hinkmar. WatTenвaCh-Levison-Löwe, Geschichtsquellen 5, S. 539 f. Devisse, Hincmar 2, S. $728-785$. MacKeon, Hincmar. Hartmann, Synoden, S. 321-327. Fuhrmann, Einfluß 1, S. 219-224. Fuhrmann, Einfluß 3, S. 625-756. Fuhrmann, Fälscher unter sich. Zuletzt: Streitschriften Hinkmars von Reims und Hinkmars von Laon 869-871, ed. SCHIEFFER.

77 Hinkmar von Reims an Hinkmar von Laon, in: MPL 126, Sp. 516C: Rigobertus Rhemorum episcopus crudeli violentia a sede sua expulsus, et in proprietate sua non longe ab eadem urbe cum magna indigentia pluribus annis residens deguit, sed quid tale cum coepiscopis suis non egit. Fuerunt etiam alii nostra aetate ac tempore a sedibus suis pro diversis causis ad tempus expulsi, quidam etiam irrecuperabiliter abjecti, et tale quid non egerunt; [...]. 
sichtbar zu machen? Rigobert scheint gerade zu einem unabhängigen Parallelbild geworden zu sein.

\section{De iure metropolitanorum - Eine Schrift Hinkmars aus dem Jahr 876}

Im Jahr 876 zog Hinkmar dann erneut Milo heran, diesmal in seiner Schrift De iure metropolitanorum. Er verfaßte sie, nachdem Papst Johannes VIII. (872882) - im Anschluß an die Kaiserkrönung Karls des Kahlen im Dezember 875 in Rom - Erzbischof Ansegis von Sens (871-883) am 2. Januar 876 zum päpstlichen Vikar für das gesamte Frankenreich erhoben hatte. Damit durfte dieser neue Synoden einberufen und als Mittler zwischen Papst und Bischöfen fungieren. Dies mußte den Widerstand des Reimser Metropoliten auslösen, der eine solche Instanz nicht über sich dulden wollte und deshalb einmal mehr mit einer Denkschrift antwortete. ${ }^{78}$

Darin ordnet Hinkmar die Geschehnisse um Milo in einen weitaus präziseren Kontext als noch im Hadrian-Brief ein, nämlich in den kriegerischen Konflikt Karl Martells mit seinem neustrischen Rivalen im Hausmeieramt Raganfred († 731), den Karl schließlich in der Schlacht bei Vinchy 717 besiegen konnte. Der schon negativ besetzte Karl wird damit erstmals namentlich mit Milo in Verbindung gebracht. ${ }^{79}$ - Unter dem Konflikt habe auch die Kirche gelitten. Einige Bistümer seien mit Laien besetzt und aufgeteilt worden. So habe Milo - nach der Tonsur ein Kleriker, nach seinem Verhalten ein unreligiöser Laie -, der die Bistümer (episcopia) Reims und Trier gemeinsam innehatte, diese in vielen Jahren zugrundegerichtet. ${ }^{80}$

Hinkmar dürfte den ergänzenden historischen Rahmen Handschriften mit Texten der fränkischen Geschichtsschreibung entnommen haben, die in Reims

78 Vgl. dazu Fuhrmann, Patriarchate II, S. $11 \mathrm{f}$. Wattenbach-Levison-Löwe, Geschichtsquellen 5, S. 537 f., 558 f. Oexle, Ansegis. Vgl. ferner Schrörs, Hinkmar, S. 364-370. Devisse, Hincmar 2, S. 664 ff. u. 811 ff. Schieffer, Ansegis. Nelson, Charles, S. 241 f., 244.

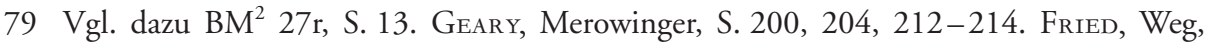
S. 202-205. Schieffer, Karolinger, S. 36-40, 44. - Raganfred suchte dann Hilfe bei Herzog Eudo von Aquitanien $(\dagger 735)$. Doch erlangte Karl einen erneuten Sieg bei Soissons. Vgl. dazu BM $\mathrm{BM}^{2} 31-31$ f, S. 13. Vgl. insgesamt auch Breysig, Jahrbücher, S. 24-28, 30-32.

80 Vgl. Hinkmar, De jure metropolitanorum, in: MPL 126, Sp. 200D: XX. [...] Denique tempore Caroli principis, quando propter discordiam et contentionem de principatu inter eum et Raganfredum, et frequentia ac civilia imo plus quam civilia, quia intestina et parricidalia bella, in Germanicis et Belgicis ac Gallicanis provinciis omnis religio Christianitatis pene fuit abolita, ita ut episcopis in paucis locis residuis, episcopia laicis donata et rebus divisa fuerint, adeo ut Milo quidam tonsura clericus, moribus, habitu, et actu irreligiosus laicus, episcopia Rhemorum ac Trevirorum usurpans insimul, per multos annos pessumdederit: [...]. 
vorhanden waren. ${ }^{81}$ Doch bietet diese Passage zwei wesentliche Neuerungen: Milo wird nun noch verschärfend mit der Begrifflichkeit eines Laien belegt und seine Amtszeit mit multos annos angegeben. Wieder vermeidet es Hinkmar, die Namen der früheren Reimser Bischöfe und diesmal auch die lange Reimser Vakanz zu nennen. Und so läßt sich nun Milos Okkupation erheblich ausweiten. Letzlich wird die lange Vakanz in Milos lange Herrschaftszeit umgewandelt. Durch Abels Fehlen läßt sich Milos im Hadrian-Brief noch erwähnte Herrschaft in Reims vor Abel mit der Vakanzzeit nach ihm - die ja schon die Denkschrift nach hinten verschiebt - jetzt vollständig zusammenaddieren. Das Milobild entwickelt nun eine Eigendynamik. Die jeweiligen Grundaussagen zur Person verschärfen und komprimieren, der historische Rahmen erweitert sich. Die Verbindung zum Bild des Hadrian-Briefes und den in den Bonifatiusbriefen erwähnten Bischöfen Grimo, Hartbert und Abel geht verloren.

\section{Der Prolog der Remigius-Vita des Hinkmar von Reims}

Schließlich führt Hinkmar Milo im Prolog der von ihm um 878 verfaßten Vita des hl. Remigius, dem Reimser Namenspatron, ein letztes Mal ins Feld. ${ }^{82}$ Die Vita basiert nach Hinkmars eigenen Angaben auf den Resten einer von ihm noch vorgefundenen älteren Remigius-Vita. ${ }^{83}$ Doch diente die neue Vita vor allem einem Zweck: dem Rückgewinn des während der Vakanz nach Ebo und in den Bruderkriegen entfremdeten Reimser Kirchenbesitzes. So werden einige Villen, die in dieser Zeit wohl verloren gingen, als frühere Erwerbungen schon durch Remigius beschrieben. ${ }^{84}$ In der Einleitung nimmt Hinkmar dann allerdings Bezug auf die Zeit Karl Martells, in der das Reimser Kirchengut bereits

81 Vgl. dazu den Liber. hist. Franc. cap. 53, ed. KRusch, S. 326-328. Fredegarii cont. cap. 10 f., ed. Krusch, S. 174 f. Vgl. auch unten S. 96 f. u. Anm. 90.

82 Vgl. zur Vita Schrörs, Hinkmar, S. 446-454. Wattenbach-Levison-Löwe, Geschichtsquellen 5, S. 519 f. Devisse, Hincmar 2, S. 1004-1037. Stratmann, Verwalter, S. 44. NonN, Remigius.

83 Vgl. dazu auch unten Anm. 85.

84 Darunter befinden sich u.a. der Reimser Fernbesitz im Mainzer Sprengel bei Kusel, Epernay und die Villa Douzy. Vgl. dazu insgesamt und ausführlich oben Kap. B.III. bei Anm. 50-52 u. 75. - Mit den Attacken gegen Milo könnte Hinkmar durchaus auch ein Argument eingesetzt haben, um den Reimser Besitz bei Kusel in der Nähe von Trier zurückzuerhalten. Das Interesse, das Hinkmar dem zunächst angeblich in Epernay bestatteten Bischof Rigobert entgegenbringt, dürfte auch mit der Absicht, diese Villa für Reims zu sichern, verbunden gewesen sein. Vgl. zu Rigobert oben zu Beginn von Kap. B.V., unten S. 95 f. u. Anm. 86 sowie die Überlieferung der Rigobert-Vita in Kap. C.III.10. - Zu weiteren Versuchen, sein Kirchengut zu sichern, vgl. Hinkmar, Collectio de raptoribus, ed. Hartmann, S. 392-394. Sie ist erstmals im Protokoll der Synode von Quierzy vom 14. Februar 857 überliefert. Vgl. ferner Stratmann, Verwalter, S. 51. 
ein erstes Mal entfremdet worden sei. Diese Zeit wird gleichsam beispielhaft als Gegenzeit, ja als Antithese zu Hinkmars Amtszeit präsentiert. Der damalige Karl sollte Hinkmars König, Karl dem Kahlen - die Wahl des Namens dürfte durchaus beabsichtigt sein - als mahnendes Beispiel dienen. In diesem Kontext tritt Milo wieder auf.

Zunächst zitiert Hinkmar dazu fast wörtlich die bereits besprochene Passage aus De iure metropolitanorum, jedoch mit einer wesentlichen Ergänzung. Die Dauer von Milos Herrschaft wird nun sogar mit per circiter XL annos angegeben. Die Reimser Kirche sei dabei in vielfacher Form geschädigt worden. Im Hadrian-Brief dagegen wird die Kirche noch während der langen Vakanz nach Abel geschädigt, der wieder fehlt! Und nur so ist es überhaupt möglich, eine derartig lange Periode anzugeben. Rigoberts Absetzung und ein Verantwortlicher dafür fehlen auch hier. Stattdessen verknüpft Hinkmar nun sein Milobild an dieser Stelle erstmals mit dem zweiten von ihm aufgebrachten Bild: dem Räuber des Kirchengutes Karl Martell in der Visio Eucherii. Unter König Pippin III. (751-768) und dem Reimser Bischof Tilpin († 794?) seien dann die verlorenen Güter restituiert worden. ${ }^{85}$

So wachsen in den untersuchten Texten Hinkmars Angaben zu Milo beständig und verändern sich langsam zu einem Bild, das es allerdings notwendig macht, im Zusammenhang mit Milos Herrschaft in Reims keine weiteren Reimser Bischöfe zu nennen. Doch von diesen verschwiegenen muß zumindest der im Brief an Hinkmar von Laon auch einmal unabhängig genannte Rigobert eine entscheidende Rolle gespielt haben. Seinen Leichnam holte Hinkmar nämlich 864 von Gernicourt - seinem angeblichen Sterbeort - nach Reims zurück. Er ließ ihn zunächst in die Kirche St-Thierry überführen, im Anschluß

85 Vgl. Hinkmar, Vita Remigii epsicopi Remensis, Praefatio, ed. Krusch, S. 251 f.: Et cum ipsa exceptio cepit lectione in populo frequentari et a multis propter brevitatis suae facilitatem transscribi, ipse magnus codex a neglegentibus neglegentius cepit haberi, usque dum tempore Karli principis, quando propter discordiam et contentionem de principatu inter eum et Ragamfredum et frequentia ac civilia, immo plus quam civilia, quia intestina et parricidalia bella, in Germanicis et Belgicis ac Gallicanis provinciis religio christianitatis pene fuit abolita, ita ut episcopis in paucis locis residuis episcopia laicis donata et per eos divisa rebus extiterint; adeo ut Milo quidam tonsura clericus, moribus, habitu et actu inreligiosus laicus episcopia Remorum ac Trevirorum usurpans insimul per XL circiter annos pessumdederit. Cuius infelici tempore de ista Remensi aecclesia non solum pretiosa queque ablata fu e $r$ u $n t$, s e d et aecclesiae atque domus religiosorum destructe et res ab episcopio f u e r e divisae. Illi quoque pauci qui erant residui clerici negotio victum querebant et denarios quos mercimonio conquirebant in cartis et librorum foliis interdum ligabant. Sicque prefatus liber cum aliis partim stillicidio putrefactus, partim soricibus conrosus, partim foliorum abscisione divisus in tantum deperiit, ut pauca et dispersa inde folia reperta fuerint. Cum vero tempore Pippini regis, predicti Karli principis filii, revelatio ostensa Eucherio Aurelianensis civitatis episcopo de dampnatione aeterna eiusdem Karli, qui res aecclesiarum diviserat, fuit, isdem Pippinus, sicut et aliarum aecclesiarum episcopiis, huic Remensi episcopio partem de rebus aecclesiasticis reddidit et Tilpinum in hac urbe Remorum episcopum ordinari consensit. 
873 nach St-Denis in Reims umbetten, wo er seitdem als Heiliger verehrt wurde. ${ }^{86}$ Um so mehr erstaunt es, daß dieser Rigobert bei Hinkmar außer im interpolierten Hadrian-Brief nie mehr gemeinsam mit Milo auftritt. Hinkmars Ursprungserzählung im Hadrian-Brief scheint sich bei ihm damit in zwei inzwischen völlig unabhängige Bilder, zum einen Milo, zum anderen Rigobert, getrennt zu haben.

\section{Die Vita Rigoberti aus dem späten 9. Jahrhundert}

Daß Rigobert für Reims aber auch nach Hinkmars Tod (882) eine ganz entscheidende Rolle gespielt haben muß, unterstreicht seine wohl von Erzbischof Fulko (883-900) zwischen 888 und 895 in Auftrag gegebene und in der Reimser Schule verfaßte Vita. ${ }^{87}$ Fulko selbst ließ Rigoberts Leichnam allerdings 883/4 von St-Denis zur Kathedrale überführen und hinter dem Kreuzaltar aufstellen. Die Kirche St-Denis selbst trug man ab, um mit dem gewonnenen Material den Wiederaufbau der Stadtbefestigung voranzutreiben. ${ }^{88}$

Die Vita bietet dann die ersten genaueren Informationen zu Rigobert überhaupt, wobei sie in ihren Anfangskapiteln wenig Konkretes sagt und eher Wundersames und Legendenhaftes zu Rigoberts Leben ausführt. Da man den Bischof in Reims aber als Heiligen verehrte, war dies letztlich auch die Aufgabe der Vita. ${ }^{89}$ Dann aber greift der Text die Geschichte von Rigoberts Absetzung auf: Als Karl Martell sich im Konflikt mit dem neustrischen Hausmeier Raganfred im Krieg befand und an Reims vorbeizog, habe ihm Rigobert nicht das Stadttor geöffnet. Karl drohte ihm mit Rache, sollte er in der Ausseinandersetzung siegreich sein. Nach der gewonnenen Schlacht von Vinchy vertrieb er

86 Flodoard II,11-15, ed. STRATMAnN, S. 156-166, schildert es ausführlich und beruft sich dabei überwiegend auf Angaben der im folgenden zu behandelnden Vita Rigoberti. Vgl. Vita Rigoberti cap. 24-26, ed. Levison, S. 75 f. Vgl. zur Vita Nonn, Bild Karl Martells, S. 116 ff. Wattenbach-Levison-Löwe, Geschichtsquellen 2, S. 168. Vgl. auch Devisse, Hincmar 2, S. 1006, der nur dieses eine Mal auf ihn eingeht. Sot, Flodoard, S. 447-458, 644 f. Schenk zu Schweinsberg, Reims, S. 150-158. Nonn, Rigobert. BAuer, Rigobert. Zur Überführung nach St-Thierry bzw. St-Denis in Reims vgl. auch Schrörs, Hinkmar, S. 461. Stratmann, Verwalter, S. 55 u. Anm. 84.

87 Zur Vita Rigoberti vgl. Anm. 86. - Zu Fulko vgl. Bur, Fulco. Schneider, Fulko, bes. auch S. 243.

88 Vgl. dazu Flodoard II,15, ed. Stratmann, S. 164 f., sowie die Vita Rigoberti cap. 28, ed. Levison, S. 77. Schneider, Fulko, S. 230, 237. Fulko ließ Rigoberts Leichnam am 15. Januar 894 erneut umbetten. Diesmal brachte man ihn zur Villa Ennemain im Vermandois in die dortige Martinskirche, ohne daß ein Grund dafür bekannt wäre.

89 Vgl. Vita Rigoberti cap. 1-8, ed. Levison, S. 61-67. Hier wird u. a. von einer Begegnung mit Pippin dem Mittleren berichtet und der Taufpatenschaft Rigoberts für Karl Martell. An einigen Stellen zitiert der Verfasser Passagen aus Hinkmars Remigius-Vita. 
Rigobert deshalb aus der Stadt. Die Angaben zum historischen Rahmen beruhen überwiegend auf dem Liber historiae Francorum, wie schon Levison anmerkte. Weitere ausfällige Bemerkungen zum Kirchengut-raubenden Karl Martell schließen sich an, wobei u. a. die Visio Eucherii ausführlich zitiert wird. ${ }^{90}$ Dann folgt ein direktes und als solches auch kenntlich gemachtes Zitat aus dem schon erwähnten Hadrian-Brief, das von der Einsetzung Milos berichtet, danach ein legendenhafter Bericht über eine Flucht Rigoberts ins Baskenland. ${ }^{91}$ Milo habe ihn dort schließlich als Gesandter Karl Martells aufgespürt und versprochen, wenn dieser ihm seinen Besitz übergebe, werde er wieder als Bischof in Reims eingesetzt. Rigobert ging darauf zunächst ein, hielt sich aber nicht daran und übertrug den Besitz nicht Milo, sondern der Kirche Christi. Deshalb erlangte Rigobert sein Bistum nicht, lebte aber auf seinem Besitz Gernicourt und durfte mit Milos Zustimmung wieder geistliche Amtshandlungen ausführen, so die Vita. ${ }^{92}$

Diese Erzählung basiert wohl weniger auf einer genauen Quellenvorlage. Vielmehr dürfte der Verfasser der Vita unter Verwendung der in Reims greifbaren Texte zu Rigobert, Karl Martell und Milo seine Erzählung geschaffen haben. Warum sonst hat sich in den wohl über 150 Jahren seit Rigoberts Tod keine Spur davon erhalten? Eine immer umfangreicher werdende Erzählung ist ohnehin verdächtig. Die Bilder vom verstoßenen Rigobert, Milo, dem Herrscher in Reims, und Karl, dem Kirchenräuber, werden hier also wieder miteinander verwoben und intensiver ausgeschmückt. Und nun wird zum ersten

90 Vgl. Vita Rigoberti cap. 9-13, ed. Levison, S. 67-70. Zu dieser Passage vgl. auch Schmidt, Trier und Reims, S. 40. Duchesne, Fastes 3, S. 85 f. - Es handelt sich um den zu den Ereignissen nahezu zeitgenössischen Lib. hist. Franc. cap. 51-53, ed. KRUSCH, S. 325-328. - Der Liber gehört zu den meistverbreiteten Texten des Mittelalters. Zu den Handschriften sowie dem Text vgl. nur Liber. hist. Franc., ed. KRusch, S. 215-238. Haupt, in: Quellen zur Geschichte des 7. und 8. Jahrhunderts, ed. Wolfram, S. 329336. Vgl. ferner Prelog, Liber historiae Francorum, mit weiterer Literatur.

91 Vgl. Vita Rigoberti cap. 14 f., ed. Levison, S. 70-72.

92 Vgl. Vita Rigoberti cap. 16-19, ed. Levison, S. 72-74, hier cap. 16, S. 72, Z. 20-33: Hunc predictus Milo abba, qui, dante Karlo, habebat Remense episcopium, repperit in eadem regione, functus apud eosdem Wascones legatione; cui et dixit: , Quid hic agis? Revertere in Frantiam, et si proprias res, quas ibi habes, michi dederis, ego tuum fatiam tibi a principe restitui episcopatum: Ad quod sanctus Domini pontifex ei respondit: ,Quascumque res inibi videor possidere, tibi dabo, si feceris quod polliceris؛. Regressus est itaque in Frantiam et in sepe memorata Gerniaca corte, peculiari possessione sua, conversabatur. Quem e vestigio adiit prefatus Milo: ,Trade', inquiens, , michi res, quas pollicitus fuisti; tibi quippe apud procerem obtinui quod spopondi. Cui beatus ait Rigobertus: ,Quotquot res habere visus fui, dedi ecclesiae Christi; non possum modo tollere ei et dare alteri. Ad quem furibundus Milo: , Quia me fefellisti, tuus nunc tibi non redhibebitur episcopatus'. Et idem mox illi dedit dignum episcopo responsum: ,Altare; aiens, , michi, queso, obtineas sanctae Mariae; de rebus episcopii factio quod volueris, unde minus curo: - Schon Mühlbacher spricht in $\mathrm{BM}^{2} 31 \mathrm{~b}, \mathrm{~S} .13$, von einem „sagenhaft[en]“ Bericht. 
Mal Karl Martell für die direkte Absetzung Rigoberts verantwortlich gemacht! Doch auch die Vita verschweigt Abel und Lando, obwohl dem Verfasser schon mit dem verwendeten Hadrian-Brief entsprechend eindeutiges Material - wenigstens zu Abel - vorgelegen haben muß. Stattdessen gibt sie Rigoberts Todesjahr fälschlicherweise mit 773 an. ${ }^{93}$ Handelt es sich dabei um einen Verschreibungsfehler? Oder soll damit zum Ausdruck gebracht werden, daß Rigobert Milo überlebt haben muß? Stiftete schlechterdings die von Hinkmar in seinen Texten immanent gebotene Chronologie Verwirrung? Hätte man unter Fulko nicht um die Lebensdaten des im späten 8. Jahrhundert amtierenden Bischofs Tilpin wissen müssen? War Rigobert vielleicht doch viel länger Bischof in Reims, vielleicht sogar bis kurz vor Einsetzung Abels 743/4??4

\section{Die Reimser Bischofsliste}

So entstanden im kulturellen Gedächtnis von Reims bis zum Ende des 9. Jahrhunderts umfangreiche Geschichtsbilder dessen, was in diesem Bistum im frühen 8. Jahrhundert geschehen sein sollte. Doch betrachtet man den zugehörigen Ausschnitt der Reimser Bischofsliste, findet sich von alledem keine Spur: [...] Lando. S. Nivardus. S. Reolus. S. Rigobertus. Tilpinus. Vulfarius. Ebo. Hincmarus. Fulco. [... $]^{95}$ Milo, Abel und Lando bleiben allesamt ungenannt. Warum? Traue man einer Angabe Hinkmars in seinem 55-Kapitelwerk, dann müsse ihm eine Fassung dieser Liste bereits bekannt gewesen sein, vermutet Duchesne. Die früheste handschriftliche Überlieferung stammt jedoch erst aus dem 11. Jahrhundert. ${ }^{96}$ Fehlt Milo, weil er unrechtmäßig in Reims herrschte? Fehlt Abel, weil er sich tatsächlich nie in Reims durchsetzte oder weil ihn Hinkmar im Zuge seines Milobildes dem Vergessen weihte? Griff Hinkmar in

93 Vgl. Vita Rigoberti cap. 19, ed. Levison, S. 74, Z. 4-8: Hic decessit pridie Nonas Ianuarii anno dominicae incarnationis circiter DCCLXXIII, indictione VIII, ibique cum debito honore a sacerdotibus et ceteris fidelibus fuit humatus, in ecclesia scilicet sancti Petri apostoli, quam ipse fundaverat, positusque est secus altare ad dexteram eius plagam. - Zum Todesjahr vgl. auch Schenk zu Schweinsberg, Reims, S. 150 u. 158. Nonn, Rigobert, Sp. 849. BAUER, Rigobert.

94 Wäre dies durch eine Verschreibung von DCCXXXXIII in DCCLXXIII zu erklären?

95 Vgl. Duchesne, Fastes 3, S. 77. Zu den älteren Bischofslisten der Provinzen Belgica und Germania vom 4. bis zum 7. Jahrhundert sowie deren Problematik vgl. auch WeIDEManN, Kirchliche Organisation, bes. S. 286, 291 u. Abb. 6, zu Reims.

96 Vgl. ebd., S. 76-80. Ebd., S. 78: Abel fehle vielleicht, weil er dem Redaktor der Liste zweifelhaft erschien. - Vgl. auch Hinkmar, Opusculum LV capitulorum adversus Hincmarum Laudunensem cap. 16, in: MPL 126, Sp. 334, sowie neuerdings Hinkmar, Opusculum LV capitulorum, ed. Schieffer, S. 190 f., worin Hinkmar eine Bischofszählung nennt. 
die Liste ein oder eine spätere Zeit? ${ }^{97}$ Vermag diese Liste womöglich auch, die langen Lebensdaten Rigoberts in dessen Vita zu erklären?

12. Flodoards „Reimser Kirchengeschichte“ aus der Mitte des 10. Jahrhunderts

Wenn der Reimser Archivar Flodoard (893/4-966) diesen Katalog - wie DuCHESNE auch angibt - tatsächlich zur Grundlage seiner Kirchengeschichte in der Mitte des 10. Jahrhunderts machte, ${ }^{98}$ dann verwundert es doch, daß er darin Abel ein ganzes Kapitel widmete. In diesem trägt er fast alle auch uns noch bekannten Belege zu ihm zusammen und meint - wie schon erwähnt -, einige hätten ihn für einen Chorbischof gehalten. ${ }^{99} \mathrm{Zu}$ Milo findet sich dagegen kein eigenes Kapitel, was man vielleicht mit seinem schlechten Ruf erklären könnte. Angaben zu ihm streuen sich über mehrere Abschnitte, die das Leben Rigoberts behandeln. ${ }^{100} \mathrm{Zu}$ Rigobert präsentiert Flodoard wohl einiges wenige Neue, doch verwendet er dazu überwiegend Material, das in Reims bereits vorhanden war: so z.B. die Vita Rigoberti. Auch zu Milo zitiert er nur bekanntes: 1. die Übergabe des Bistums durch Karl Martell an diesen, der nur nach der Tonsur Kleriker gewesen sei, unter Verwendung des Hadrian-Briefes; hinzugefügt wird allerdings, Milo sei von Karl für seine Gefolgschaft im Krieg belohnt worden; ${ }^{101}$ 2. die Antwort de Milone autem et eiusmodi similibus im Brief des Zacharias an Bonifatius, ${ }^{102}$ 3. Milos Aufenthalt im Baskenland und die gemeinsame Rückkehr mit Rigobert nach der Rigobert-Vita ${ }^{103}$ und schließlich 4. die schon im 14. Kapitel der Rigobert-Vita zitierte Passage zu Milo nach dem interpolierten Hadrian-Brief. ${ }^{104}$ Erstaunlicherweise aber bleiben die weiteren, bereits disku-

97 Vgl. zum Fehlen Milos in der Liste auch Ewig, Milo, S. 416. Schenk zu Schweinsberg, Reims, S. 164. Vgl. dagegen WInHELlER, Lebensbeschreibungen, S. 87 f.

98 Vgl. dazu Duchesne, Fastes 3, S. 76. Vgl. dazu auch Flodoard, ed. Stratmann, S. 12 f. - Zu Flodoard vgl. bereits oben S. 80 u. Anm. 45.

99 Vgl. Flodoard II,16, ed. Stratmann, S. 166 f. Zitiert werden die entsprechenden Bonifatiusbriefe sowie der Abschnitt aus dem Hadrian-Brief. - Es fehlen allerdings der Brief des Bonifatius an Æthelbald von Mercien und der Text der Synode von Soissons. - Vgl. dazu oben S. 72 f., 80 u. Anm. 19 f. sowie 45.

100 Vgl. Flodoard II,11-15, ed. Stratmann, S. 156 f.

101 Vgl. Flodoard II,12, ed. Stratmann, S. 160, Z. 12-16: Prefatus itaque Karolus ut principatum bello adeptus est, hunc virum domini Rigobertum patronum suum, qui, ut traditur, eum de lavacro sancto susceperat, episcopatu deturbavit et cuidam Miloni, sola tonsura clerico, quod secum processerat ad bellum, dedit episcopium hoc.

102 Vgl. Flodoard II,12, ed. Stratmann, S. 161. Zum Wortlaut vgl. oben S. 71 f. u. Anm. 18.

103 Vgl. Flodoard II,12, ed. Stratmann, S. $161 \mathrm{f}$. Der Text lehnt sich an den der Vita Rigoberti cap. 16, ed. Krusch, S. 72, an.

104 Vgl. Flodoard II,13, ed. Stratmann, S. 162 f. Vgl. dazu Vita Rigoberti cap. 14, ed. LEVISON, S. $70 \mathrm{f}$. 
tierten Schriften Hinkmars unberücksichtigt. Flodoard liefert zu Milo somit keine neuen Angaben, sondern faßt lediglich für ihn greifbare Materialien zusammen.

\section{Ergebnis}

Damit ist das Ende des zweiten Abschnitts erreicht. Zusammenfassend läßt sich also erkennen, wie nach nur zwei sicheren Quellen zu Milo im 8. Jahrhundert von denen eine nicht einmal dessen Funktion nennt, die andere undeutlich bleibt - gegenüber vier Belegen für einen Reimser Bischof Abel dann im 9. Jahrhundert geradezu eine Quellenflut einsetzte. Doch ist diese auf Reims und vor allem den dortigen Erzbischof Hinkmar beschränkt. Vom HadrianBrief bis zur Remigius-Vita verändern sich die von ihm entworfenen und konstruierten Milobilder immer mehr, werden immer negativer. Hinkmar ging es offenbar nicht darum, daß diese Bilder insgesamt eine Kohärenz aufwiesen, wie sie die Forschung mit ihren widersprüchlichen Ergebnissen herzustellen versucht hat. Vielmehr setzte er Milo immer wieder neu in Bezug zu seiner jeweils eigenen zeitlichen Situation und paßte ihn entsprechend daran an. Man könnte von situativen Bildern sprechen, wie er überhaupt oft - z. B. in der Visio Eucherii - mit solchen Bildern arbeitete. Hinkmar projizierte also die Probleme seiner eigenen Zeit als Bild in die Vergangenheit, um sie von dort wieder auf seine Gegenwart zurückwirken zu lassen. Diese Bilder verfügten also tatsächlich über eine ganz eigene Wahrheit. Er wollte keine Reimser Bistumsgeschichte schreiben. Bei seinen Problemen, seiner Motivation stand der Rückgewinn von entfremdetem Reimser Kirchengut im Vordergrund. Dazu konstruierte er das abschreckende Bild einer desolaten Kirche sowie eines vakanten oder unrechtmäßig verwalteten Bistums und eines Despoten, der Kirchengut entfremdete. Es ist aber nicht völlig abwegig, daß auch der Primatsstreit mit Thietgaud von Trier seine Spuren hinterließ. Man darf sogar noch weitere Schichten annehmen. Beim Aufbau seiner Bilder zog Hinkmar nachweisbar Textquellen heran und erfand nicht frei. Um so mehr stellt sich dann aber die Frage, wieso er ausgerechnet Milo als unrechtmäßigen Verwalter oder Bischof in Reims und Trier wählte. Verfügte er noch über eine oder mehrere Vorlagen, die wir nicht mehr kennen? Finden diese sich noch in der Chronologie des Hadrian-Briefes wieder? In jedem Fall schuf er einen Milo, den es so wohl niemals gegeben hatte und implantierte sein Bild ins kollektive und damit auch ins kulturelle Gedächtnis von Reims, von wo aus es über die Vita Rigoberti hinaus dann weiter wirkte. 


\section{Die Trierer Überlieferung zu Milo seit dem 10. Jahrhundert}

Denn nicht in Reims sollte ein letztes Mal an Bischof Milo erinnert werden. Nach langem Schweigen rief man ihn sich in Trier - seinem angeblichen Herkunftsort, traut man der undeutlichen Urkunde Karls des Großen (DKarol. I 148) - seit dem ausgehenden 10. Jahrhundert wieder oder eben vielleicht zum ersten Mal ins Gedächtnis. Was geschah inzwischen? Offenbar gab es bisher keinen Anlaß, seiner zu gedenken. Doch mit den sich zunehmend weiter verbreitenden Reimser Texten und Handschriften war es wohl nur eine Frage der Zeit, bis Milo auch in Trier interessant werden mußte. ${ }^{105}$ Dieser dritten Ebene soll nun noch in einem Ausblick nachgegangen werden.

\section{Die Trierer Bischofsliste}

So erscheint Milo erstmals in einer Trierer Bischofsliste, die wohl unter dem dortigen Erzbischof Egbert (977-993) aufgezeichnet wurde. Hier ein Auszug: [...] Numerianus. Basinus. Liutwinus. Milo. Wiomadus. Rimbodus. Wizo. [...] $]^{106}$ Egbert interessierte sich ganz offensichtlich für die Trierer Bischofsgenealogie. Denn im sog. Egbert-Psalter, den er selbst in Auftrag gab, finden sich als Illustrationen einige ausgewählte Amtsvorgänger, offenbar aber nur diejenigen, die als heilig verehrt wurden. ${ }^{107}$ Milo ist nicht darunter. Egbert ließ auch den von ihm erworbenen Teil des Petrusstabes mit Goldblech umkleiden, auf dem zum einen eine verkürzte Papstgenealogie, zum anderen wieder die Bischöfe des Psalters eingeprägt sind. Auch diesmal fehlt Milo. ${ }^{108}$ Er wurde also erinnert, scheint aber noch nicht von hervorgehobenem Interesse gewesen zu sein.

105 Zur Verbreitung von Flodoard vgl. Flodoard, ed. Stratmann, S. 31 ff., sowie die der Vita Remigii ebd., S. 239-250.

106 Vgl. Duchesne, Fastes 3, S. 33. Vgl. ebd., S. 30-32, zu den Handschriften, deren älteste mit einer Listenfassung, die mit Egbert endet, die Datierung begründet. Zu Milo vgl. ebd., S. 39. Zu den älteren Bischofslisten der Provinzen Belgica und Germania sowie deren Problematik vgl. nochmals Weidemann, Kirchliche Organisation, bes. S. 286 u. Abb. 7, zu Trier. - Zu Egbert vgl. hier nur Heit, Egbert. Ronig, Egbert. Schließlich: Egbert Erzbischof von Trier 977-993, ed. Ronig, sowie ausführlich unten Kap. D.VI.3.a.

107 Diese Heiligen wurden in einer zweiten Fassung der Bischofsliste auch als solche gekennzeichnet. Vgl. Duchesne, Fastes 3, S. 31. - Vgl. zur Bischofsliste ausführlich unten Kap. D.VI.3.e.

108 Vgl. zum Psalter und dem Petrusstab unten Kap. D.VI.3.c. - f., sowie hier nur WEStermann-Angerhausen, Goldschmiedearbeiten, S. 34-40, 102-107, 129-134. Ronig, Psalter. Lauer/Hefele, Petrusstab. 


\section{Die Vita Liutwini I aus Mettlach}

Dies änderte sich wohl langsam mit der am Ende des 10. oder zu Beginn des 11. Jahrhunderts entstandenen ältesten Liutwin-Vita eines bislang unbekannten Mettlacher Mönchs. ${ }^{109}$ Die Vita beschäftigt sich als erster Text überhaupt genauer mit Liutwin, Milos angenommenem Amtsvorgänger und Vater, und könnte vielleicht in Zusammenhang mit Liutwins hervorgehobener Memoria unter Egbert stehen. Der Verfasser bekennt allerdings, daß ihm keine genauere schriftliche Überlieferung zu seinem Protagonisten vorliege. Man könne lediglich auf mündliche Erzählungen zurückgreifen. Dabei wird seine frühe Lebensgeschichte erzählt und, wie er Mettlach gründete. Doch wäre erst mit den dann ebenfalls in der Urkunde Karls des Großen (DKarol. I 148) erwähnten testamentarischen Schenkungen an Trier ein Vorgang angegeben, der sich anhand einer (vermutlich im wesentlichen zeitgenössischen) Vergleichsquelle überprüfen ließe. ${ }^{110}$

Offenbar gab es irgendeine Liutwintradition in Mettlach oder im Trierer Raum, die weitere Elemente aufgenommen hatte. Denn Liutwin wird in der Vita als Bischof von Trier, Reims und Laon erinnert. ${ }^{111}$ Dies ist aber schon aufgrund von Rigoberts dann zeitgleichem Episkopat für Reims unwahrscheinlich. Zu Recht deutet Anton dies als Rückprojektion der Angaben zu Milo auf Liutwin. ${ }^{112} \mathrm{Zu}$ klären bliebe dennoch, warum Laon hinzukommt. ${ }^{113}$

109 Vgl. ausführlich zur Vita, deren genauer Entstehungszeit sowie zu weiterer Literatur unten Kap. D.IX.2. - Zu Liutwin insgesamt vgl. Anton, Liutwin. Vgl. bes. auch Gresser, Liutwin, der die gesamte Trierer Überlieferung ohne Prüfung in seinen Lexikonartikel eingearbeitet hat.

$110 \mathrm{Zu}$ den von der Vita selbst angegebenen Quellen vgl. Vita Liutwini I cap. 2, ed. Perier, S. 169D. Vgl. die Zusammenfassung des Vitenberichtes auch bei Winheller, Lebensbeschreibungen, S. $87 \mathrm{f}$.

111 Vgl. Vita Liutwini I cap. 14, ed. Perier, S. 171C-D: Cum ergo omnium discretionis examine subditorum corda rexerat, flagrantiaque virtutum adeo finitimos quosque illexerat, ut Remenses pariterque Laudunenses cives, qui populi nuper caruerant pastore, ipsius se rectissimo moderari peterent regimine.

112 Vgl. Anton, Liutwin, S. 51. Schon Winheller, Lebensbeschreibungen, S. 89, hält das für unglaubwürdig. Ebd., S. 90 f., äußert er sich kritisch zum Inhalt der Vita, wie auch Sснмidt, Trier und Reims, S. 41 f. Gauthier, Évangélisation, S. 361. - Für glaubwürdig halten es allerdings Ewig, Milo, S. 194 f. Semmler, Sukzessionskrise, S. 26. Scheibelreiter, Bischof, S. 158, Anm. 117.

$113 \mathrm{Zu}$ klären bleibt auch, warum in einer kanonistisch versierten Zeit wie dem 10. Jahrhundert überhaupt die Doppelbesetzung eines Bistums kritiklos hingenommen wurde. Vgl. hierzu ausführlich Scholz, Transmigration, der die Geschichte des Verbots des Bistumswechsels sowie der Doppelbesetzung seit den frühen Synoden und Konzilien ausführlich untersucht. Ebd., S. 102-187, behandelt er die Zeit des 9.-10. Jahrhunderts genauer. Zwar waren Bistumswechsel sowie Doppel- und Mehrfachbesetzungen grundsätzlich durch die Kanones verboten, dennoch ließen sie sich nicht vollständig unter- 
Es zeigt aber auch, daß an zwei verschiedenen Orten zwei teils unabhängige Geschichtsbilder von einer gemeinsamen Basis ausgehen können. Diese Basis läßt sich für Mettlach unschwer erkennen: Milo habe vierzig Jahre Trier und Reims gemeinsam verwaltet. Der Autor verwendete also zweifellos die Einleitung der Remigius-Vita. ${ }^{114}$ Doch seine dann eigenen Ausführungen gehen über diesen Text hinaus: Milo sei, wie einige sagen, vom väterlichen Pfad der Tugend abgeirrt. Dann allerdings betont der Verfasser Milos besondere Fürsorge für Trier, schließlich auch die Translation seines angeblich in Reims verstorbenen Vaters nach Trier, der auf wundersame Weise weiter nach Mettlach gelangt sei. $^{115}$

\section{Der Libellus de rebus Treverensibus aus dem Trierer Erzstift}

In der Chronologie der Quellen folgt nun der ganz zu Anfang zitierte und im dritten Viertel des 11. Jahrhunderts in Trier selbst entstandene Libellus de rebus Treverensibus. ${ }^{116}$ Neben der Meldung von Milos Tod durch einen Eber und dessen Bestattung in Ehrang, die hier erstmals überhaupt erscheint, bietet der Libellus gegenüber der Liutwin-Vita zahlreiche weitere Angaben, die auf einer breiteren Quellenbasis beruhen. Diese bilden über die Remigius-Vita hinaus nun auch Flodoards Kirchengeschichte - vermittelt durch ihn auch die Rigo-

binden. Allerdings wurden sie immer als ausgesprochen problematisch wahrgenommen und bedurften der besonderen Begründung einer Synode oder des Papstes. Als Beispiel denke man für das 10. Jahrhundert nur an den bekannten und umstrittenen Wechsel Giselhers von Merseburg 981 nach Magdeburg, nachdem Merseburg als Bistum aufgehoben worden war (dazu bes. ebd., S. 177 ff.).

114 Vgl. so schon Winheller, Lebensbeschreibungen, S. 92.

115 Vgl. Vita Liutwini I cap. 16 f., ed. Perier, S. 171 f., hier cap. 16, S. 171E-F: Cui erat jam filius, nomine Milo, qui, ut quidam dicunt, nimis degener a paternae rectitudinis semita oberraverat tramite malo; quamvis relinqueretur heres rerum \& successor honorum. Nam Patri succedens Treverensium \& Remorum pariter episcopatum per quadraginta annos tenuit, \& Trevericis Patris sui exuvias ad primae sponsae suae sedem revehendas satis efficax adjutor fuit. Treverici itaque comperto almi Praesulis obitu, paterno mox commoti affectu, ad Remensem concite urbem cum Milone properarunt, \& sacrum thesaurum, cum magna difficultate sed nutu Dei acquisitum, ad propria asportarunt. Tandem cum propriae civitati sanctum Pontificem prospere inveherent \& digne loco, quo praesidebat, collocare vellent, difficultatem passi, nullo modo id valebant efficere; quia revera locum humiliationis potius, quam honoris, videbatur appetere. Consilio igitur inter primores de tam inopinata re habito, pignus sanctissimum, sublato remige, imposuerunt navigio, in commune Gubernatorem mundi rogantes, ut illuc, quo voluntas ejus esset, annueret dirigi. - Doch klingt dies eher nach der Ausbildung einer Heiligenlegende. In der Vita fallen zudem zahlreiche chronologische Unstimmigkeiten auf.

116 Vgl. dazu schon oben S. 66 u. Anm. 1 sowie noch ausführlicher unten Kap. D.IX.3. 
bert-Vita - sowie der Liber historiae Francorum. ${ }^{117}$ Das erste Kapitel des Libellus' folgt denn auch überwiegend dem Liber sowie Flodoard und berichtet über Karl Martell, die Schlacht von Vinchy, die Absetzung Rigoberts und die Einsetzung Milos in Reims. Doch dort hinein erfolgt ein Einschub: Der weltliche Milo sei Sohn Liutwins, der Mettlach gegründet und nach seinem Onkel, dem Trierer Erzbischof Basin, nicht nur Trier, sondern auch die Bistümer Reims und Laon innegehabt habe. Diese Information scheint aus der Liutwin-Vita einzufließen und steht inhaltlich völlig im Widerspruch zur Bistumsübergabe durch Karl an Milo sowie zur vorausgehend erwähnten Herrschaft Rigoberts. Doch löst der unbekannte Verfasser das nicht auf. ${ }^{118}$ Der Libellus folgt dann weiter dem Liber, Flodoard und der Remigius-Vita. Insgesamt haftet Milo schon ein schlechter Ruf an. Er wird sogar als quondam nostre Treverice civitatis pervasoris ${ }^{119}$ bezeichnet, was wiederum die Reimser Bilder noch nicht beinhalteten. Erst einige Kapitel später und ganz unabhängig steht der kurze Einschub zu Milos Tod. ${ }^{120}$ Der in Trier inzwischen rezipierte Flodoard hatte das Bild Milos also weiter verändert. Man versuchte dennoch, die eigene lokale Überlieferung in dieses Bild einzupassen, wobei der von außen herangetragene schlechte Ruf Milos möglicherweise den Anlaß zur Entstehung neuer regionaler Traditionen wie der Eber-Erzählung bot.

117 Vgl. dazu nur die Anmerkungen in der Edition: De rebus Treverensibus saec. VIII-X libellus cap. 1-3, ed. Wartz, S. $99 \mathrm{f}$.

$118 \mathrm{Zu}$ Milo vgl. De rebus Treverensibus saec. VIII-X libellus cap. 1 f., ed. WAitz, S. 99 f., der Einschub hier cap. 1, S. 99, Z. 25-33: [...] Copioso igitur Karolus adunato exercitu, ut in Gestis Francorum legitur, Hilpericum in loco dicto Vinciaco cum multis regni sui nobilius convenit; inter quos, ut [ab hier beginnt der neue Zusatz:] Remensis docet historia, erat Milo, genere clarus, sed acer et irreligiosus, qui postmodum circiter quadraginta annos Treverensem et Remensem episcopatum tenuit, filius domni Liutwini quondam ducis, qui, assumpto religionis habitu, in loco qui dicitur Medelocus in aecclesia apostolorum Petri et Pauli, quam ipse fundaverat et copiose ditaverat, cum multis aliis quos illuc congregaverat monachis monachus Deo militavit. Unde, decedente Basino avunculo suo, Trevirorum archiepiscopo, episcopus assumptus, non solum hanc Treverensem, sed et Remensem atque Ludunensem aecclesiam gubernavit.

119 Vgl. De rebus Treverensibus saec. VIII-X libellus cap. 2, ed. Wartz, S. 100, Z. 20 f., ähnlich Z. 15. In cap. 3, S. 100, Z. 47-56, wird aus Flodoard auch Hinkmars Brief an Papst Nikolaus I. zitiert sowie der kurze Abschnitt über Milo im Brief des Papstes Zacharias I. an Bonifatius.

120 Vgl. ebd. cap. 9, S. 102 f., wobei bezeichnenderweise eine Kurzfassung der Visio Eucherii vorausgeht. 


\section{Die Miracula s. Liutwini aus Mettlach}

Diesen zwischen den Reimser und Trierer Bildern erkennbaren Konflikt im kollektiven bzw. kulturellen Gedächtnis versuchten auch die Miracula s. Liutwini aufzulösen, die in Mettlach von einem bislang unbekannten Mönch bis spätestens 1095 verfaßt wurden. ${ }^{121}$ Liutwin erscheint darin nicht mehr als Bischof dreier Bistümer. Verfügte der Verfasser etwa nicht über die Liutwin-Vita, oder erkannte er die falsche Information? Es fällt auch kein Wort zu Rigobert. Hatte denn eine Handschrift von Flodoards "Reimser Kirchengeschichte" Mettlach noch nicht erreicht? Liutwins Sohn Milo habe man in guter Erinnerung, wenn auch Hinkmar in der Einleitung zur Remigius-Vita ein schlechtes Urteil über ihn fälle, so der Text. Milos Ende erschiene nicht deshalb als berüchtigt, weil er auf der Jagd von einem wilden Eber getötet wurde. Da er nämlich gerecht war, befinde er sich in der ewigen Glückseligkeit. Von Milo sei dem Kloster sehr viel Gutes widerfahren. Er sei ein „frommer Erbe“ des vom Vater Hinterlassenen gewesen. Nach Milo habe man die Mettlacher Äbte des Trierer Bistums für würdig gehalten. ${ }^{122}$

Zum einen wußte man in Mettlach also von Hinkmars Urteil über Milo. Zum anderen war nun bereits der Tod durch einen Eber bekannt. Bei letztem muß es sich aber um eine Trierer Tradition handeln, sonst würde der Verfasser der Miracula nicht versuchen, Milo davon reinzuwaschen. Vom Begräbnis in Ehrang fehlt allerdings jedes Wort. Dennoch verhielt sich die Mettlacher Überlieferung Milo gegenüber zu diesem Zeitpunkt noch positiv. Warum? Begann man, sich erst im Zuge von Egberts Genealogien wieder an die eigenen Vorfahren zu erinnern? Mußte nicht der Sohn des eigenen und heiligen

$121 \mathrm{Zu}$ Mettlach vgl. hier nur RaAch, Mettlach. Herrmann, Mettlach. - Zur Entstehung der Miracula vgl. Winheller, Lebensbeschreibungen, S. 95. RAach, Mettlach, S. 7. Anton, Liutwin, S. 35 u. Anm. 42, sowie ausführlich unten Kap. D.IX.4.a. Zu den Miracula insgesamt vgl. unten Kap. D.IX.4.

122 Miracula s. Liutwini auct. Monacho Mediolacensi, ed. SAuerland, S. 1261-1268, hier cap. 3, S. 1262, Z. 4-16: Milonis autem, filii eius, finis et actus est memoria dignus, quamvis Hincmarus Remorum episcopus perversorem eum episcopatus sui describit, cum de eo in prologo Vite sancti Remigii talia dicit: Et Milo quidam, tonsura clericus, actione autem irreligiosus laicus, per quadraginta annos Treverensium pariter et Remorum episcopatum pessundederat. Cuius etiam finis non ideo infamis extitit, quod canes sequentem aper silvaticus extinxit; quia iustus, quacunque morte preoccupatus fuerit, in refrigerio erit. A quo multum utilitatis accepimus loco nostro collatum, multum esse honoris audivimus impensum. Quod enim pietatis studio non proveheret sibi relicta, qui paterna pius heres gubernanda suscepit ut propria. Attamen tali amore genitorisque eius Treverenses flamma accenderat talisque affectus circa Mediolacenses illos constrinxerat, ut per longa annorum spacia ob amorem eius quasi pie consuetudinis haberent legittimum, decedentibus illorum pastoribus, de Mediolacu eligere sibi patronum. Qicunque enim Mediolacensium abbatis fungebatur officio, Treverensium dignus estimabatur episcopio. Vgl. auch Schenk zu Schweinsberg, Reims, S. 165 f., der auf das etwas positivere Urteil in Trier hinweist. 
Gründers Liutwin auch selbst in guter Erinnerung bleiben? Um das genauer zu klären, bleibt nur der Weg zu prüfen, was im Umfeld Egberts in Trier und Mettlach geschehen sein mag. Dies wird weiter unten erfolgen. ${ }^{123}$

Der noch verhältnismäßig positiven Mettlacher Erinnerung an Milo stehen die negativen Reimser und inzwischen auch Trierer Überlieferungen gegenüber. Man könnte sagen, im kollektiven Gedächtnis Mettlachs und zuvor schon Triers fand ein Aushandlungsprozeß zu Milo statt. Spuren dieses Prozesses und seines allmählichen Wandels lassen sich sowohl im Libellus wie auch in den Miracula nachvollziehen. Dabei wirkt das Trierer Bild insgesamt schon weitaus negativer als das Mettlacher, wobei sich als mögliche Erklärung eine stärkere Rezeption Reimser Texte in Trier anböte.

\section{Die Gesta Treverorum aus Trier}

Die um 1100 im Kloster St. Eucharius vor Trier verfaßte Redaktion A der Gesta Treverorum schließlich zeigt dann den weiteren Wandel im kollektiven Gedächtnis: ${ }^{124}$ Dem Bischof Basin folge sein Neffe Liutwin, Mettlachs Gründer, der auch zum Bischof von Reims und Laon gewählt worden sei. Nachdem er in Reims gestorben sei, habe sein Sohn Milo ihn zunächst nach Trier geholt und anschließend in Mettlach begraben. Milo sei dann Bischof in Trier und Reims geworden. $\mathrm{Zu}$ Beginn habe er dabei seinen Vater nachgeahmt, sei dann aber zum Gewaltherrscher geworden. Zu dieser Zeit habe es schwere Kriege in dieser Provinz gegeben. Der Tyrann Karl gab nun Laien Bistümer und ließ den Bischöfen keine Macht. Der ungläubige Milo brach mit Karl in den Krieg auf und erhielt nach gewonnener Schlacht die Bistümer Trier und Reims. Es folgt eine dezidierte Beschreibung seines unheilvollen Wirkens. Papst Zacharias I. setzte deshalb Bonifatius als Verwalter der Trierer und Reimser Kirche ein. Nach einigen weiteren Bemerkungen - u.a. zu Bonifatius - schließt sich endlich Milos durch den Eber herbeigeführter Tod nach vierzigjähriger Herrschaft an und sein Begräbnis in Ehrang. ${ }^{125}$

123 Eine solche Prüfung kann aber nur auf der Basis der Miracula erfolgen, die auch über das Kloster zur Zeit Egberts berichten. Vgl. dazu die Miracula s. Liutwini auct. Monacho Mediolacensi cap. 12 -16, ed. SAuerland, S. 1265 f. Vgl. ferner RaACH, Mettlach, bes. S. 45-52. Vgl. schließlich zur angekündigten Prüfung ausführlich unten Kap. D.IX.4.b.

$124 \mathrm{Zu}$ den Gesta vgl. schon oben S. 66 f. u. Anm. 3 f. sowie ausführlich unten Kap. D.IX.6.

125 Vgl. Gesta Treverorum cap. 24 f., ed. Wartz, S. 161 f.: 24. [...] - Huic successit Numerianus; cui Basinus; post quem Liutwinus, Basini ex sorore nepos. Hic primo Belgicae Galliae dux, omnia monasteria huius urbis largissimis honoravit donariis et praediis auxit. Postea super fluvium Saroam in proprio suo congregationem monachorum instituit, ubi et ipse monasticae vitae habitum suscepit. Defuncto avunculo suo Basino episcopo successit, electus etiam a Remensibus et Laudunensibus praefuit; in quibus duobus uno die, Deo 
Man könnte die Dinge hier bis ins einzelne verfolgen, was später noch geschehen soll. ${ }^{126}$ Doch läßt sich bereits nach dieser kurzen Paraphrase erkennen, daß nun die vorgefundenen Mettlacher, Reimser und Trierer Bilder stimmig gemacht, ausgehandelt, ja zu neuen Bildern harmonisiert werden. Der angeblich abgesetzte Bischof Rigobert, der das Gesamtbild erschweren würde, bleibt unerwähnt und soll vergessen werden, obwohl die Gesta Flodoards Kirchengeschichte benutzten. Nur so aber kann Liutwin schon früh drei Bistümer innehaben und Milo ihm in zweien folgen. Beide - nicht nur Reims - erhält er jetzt von Karl Martell. Milo macht zudem einen langsamen Mentalitätswandel vom guten zum schlechten Menschen durch. Das kollektive Gedächtnis arbeitet

praestante, sacrorum ordinum consecrationem celebravit. Remis obiit, et a Milone filio et Treberensibus relatus, divino dato indicio, ad Mediolacum sepultus est. Post quem Milo, filius eius, sacerdotali functus est officio apud Trebiros et Remos, primo quidem imitator patris, deinde tirannus effectus est, nichilque in eodem de clericali honore vel vita nisi sola tonsura enituit. Eo enim tempore bella gravia et intestina parricidalia in hac provintia orta sunt, quando Karolus tirannus laicis episcopatus donavit, et episcopos nullam potestatem habere permisit. Cum hoc Karolo Milo supradictus ad bellum profectus est, sola tonsura iam clericus, habitu et moribus inreligiosus laicus, et post victoriam episcopatibus Trebirorum et Remorum ab eodem Karolo donatus est. Cuius infelici tempore de his ecclesiis multa sunt ablata, et res ab episcopiis divisae, domus religiosorum destructae, ecclesiastica disciplina dispertita, adeo ut clerici, sacerdotes, monachi et moniales sine lege ecclesiastica viverent et refugia indebita haberent. Patet huius calamitatis indicium in plurimis Treberensis parrochiae ecclesiis, in quibus singulis singulae fuerant olim congregationes, quae tam a praefato Milone quam ab aliis tirannis, ne dicam episcopis, rebus spoliatae, vix unum presbiterum possunt sustentare, sicut sunt ecclesia sancti Medardi quae sita est prope cellam sancti Eucharii, ecclesia super Saroam quae dicitur Tavena, ecclesia sancti Simphoriani a beato Modowaldo constructa, ecclesia in honore sanctae Crucis iussu beatae Helenae condita, ecclesia sancti Remigii ad litus Mosellae, [ecclesia ad palacium, ecclesia super montem sancti Beati, ecclesia] sancti Stephani extra castrum Andernacum. Forum quoque, quod erat ante portam Mediam constitutum et frequentia comprovincialium satis celebre et famosum, orta inter cives et negotiatores gravi simultate, ex eo loco in Wagasatiam translatum est. Et de his actenus.

25. Zacharias papa beatum Bonifacium, doctrina et operatione clarum, Treberensi et Remensi ecclesiis visitatorem et spiritualium negotiorum provisorem constituit, cum Milo tirannus res utrarumque teneret. Interea Karolus ecclesiarum destructor moritur. De quo nocte quadam revelatum est sancto Eucherio Aurelianensi episcopo, quia esset in inferno inferiori. Qui accito domno Bonifacio, Romanae sedis vicario, aliisque boni testimonii viris, sepulchrum Karoli aperuit. Sublato autem lapide, serpens mirae magnitudinis exivit de sarcophago, corpus autem Karoli non est ibi inventum. In his diebus domnus Zacharias papa audiens fidem et doctrinam domni Bonifacii, constituit eum archiepiscopum Mogontinae ecclesiae. Nam antea Mogontini episcopi et Colonienses suffraganei erant Wormaciensium episcoporum. Milo igitur tirannus, his ita peractis, venationi inserviens, ab apro percussus moritur in villa quae dicitur Arno primo a Treberi miliario, ubi et sepelitur post 40 annos suae tirannicae invasionis.

126 Vgl. nochmals unten Kap. D.IX.6. 
also beständig und kreiert Bilder von Milo, die nur noch wenig von der vermutlichen Trierer Gestalt des 8. Jahrhunderts übrig lassen. ${ }^{127}$

\section{Ergebnis}

Wir sind also wieder beim Ausgangspunkt der Überlegungen, dem vermeintlichen Grab Milos in Ehrang, angekommen. Einen angeblich dort bestatteten Bischof Milo gab es so wohl nie. Vielmehr handelt es sich um Trierer Geschichtsbilder, die im Laufe des 10. oder 11. Jahrhunderts entstanden und deren genauer Ursprung u. a. im folgenden noch zu überprüfen sein wird. In jedem Fall griffen diese Bilder bereits auf Reimser Bilder des 9. und 10. Jahrhunderts zurück, die der dortige Erzbischof Hinkmar maßgeblich konstruiert und geprägt hatte. Um so mehr verbietet es sich dann - wie es die bisherige Forschung getan hat -, aus allen diesen Quellen und ihren Einzelbildern, ohne ihrem jeweiligen zeitlichen Entstehungshorizont nachzugehen, ein Bildpanorama zusammenzusetzen, das eben jeder einzelnen dieser Quellen hat gerecht werden wollen und es doch nicht geworden ist. Auf viele der gestellten Fragen kann deshalb keine oder noch keine Antwort gegeben werden. Auch dieser Milo hat nie existiert. Er ist die Erfindung des modernen Historikers. Wo Milo tatsächlich begraben wurde, läßt sich im Augenblick nur vermuten: vielleicht in der Trierer Kathedrale oder im Kloster Mettlach. In den nun folgenden Überlegungen zu Liutwin und Basin kommen wir aber einer Antwort vielleicht schon etwas näher.

127 Die Fassungen B und C der Gesta lassen Milo schließlich auch - nach der Vertreibung Chlodulfs von Metz - zum Metzer Bischof werden. Vgl. dazu Gesta Treverorum cap. 24, ed. Waitz, S. 161, Anm. ${ }^{* *}$. 